Review

\title{
PHF6 Degrees of Separation: The Multifaceted Roles of a Chromatin Adaptor Protein
}

\author{
Matthew A.M. Todd ${ }^{1,2}$, Danton Ivanochko ${ }^{1,2}$ and David J. Picketts ${ }^{1,2,3, *}$
}

1 Regenerative Medicine Program, Ottawa Hospital Research Institute, Ottawa, Ontario, K1H 8L6, Canada; E-Mails: mtodd.research@gmail.com (M.A.M.T.); divan061@uottawa.ca (D.I.)

2 Department of Biochemistry, Microbiology, and Immunology, Faculty of Medicine, University of Ottawa, Ontario, K1H 8M5, Canada

3 Department of Cellular and Molecular Medicine, Faculty of Medicine, University of Ottawa, Ontario, K1H 8M5, Canada

* Author to whom correspondence should be addressed; E-Mail: dpicketts@ohri.ca;

Tel.: +1-613-737-8989; Fax: +1-613-737-8803.

Academic Editor: Jessica Tyler

Received: 30 April 2015 / Accepted: 16 June 2015 / Published: 19 June 2015

\begin{abstract}
The importance of chromatin regulation to human disease is highlighted by the growing number of mutations identified in genes encoding chromatin remodeling proteins. While such mutations were first identified in severe developmental disorders, or in specific cancers, several genes have been implicated in both, including the plant homeodomain finger protein 6 (PHFO) gene. Indeed, germline mutations in PHF6 are the cause of the Börjeson-Forssman-Lehmann X-linked intellectual disability syndrome (BFLS), while somatic PHF6 mutations have been identified in T-cell acute lymphoblastic leukemia (T-ALL) and acute myeloid leukemia (AML). Studies from different groups over the last few years have made a significant impact towards a functional understanding of PHF6 protein function. In this review, we summarize the current knowledge of PHF6 with particular emphasis on how it interfaces with a distinct set of interacting partners and its functional roles in the nucleoplasm and nucleolus. Overall, PHF6 is emerging as a key chromatin adaptor protein critical to the regulation of neurogenesis and hematopoiesis.
\end{abstract}

Keywords: AML; BFLS; hematopoiesis; neurogenesis; nucleolus; NuRD; PAF1; PHF6; T-ALL; XLID 


\section{Introduction}

Mutations in proteins that chemically modify chromatin, or possess reader domains to bind these modifications are now documented in a growing number of developmental diseases [1]. More recently, the high-throughput screening of various cancer genomes using next-generation screening technologies (e.g., Roche/454, Illumina/Solexa) has yielded mutations in many of these same epigenetic regulators [2-4]. These mutations target genes encoding proteins that are responsible for ATP-dependent nucleosome reorganization (e.g., ATRX), histone tail modifiers (e.g., JARID1C), histone variants (e.g., histone H3.3), DNA methyltransferases (e.g., DNMT3A/B), and proteins that interface with chromatin (e.g., MECP2) [4-8]. Here, we review recent advances in a gene that encodes another such protein, plant homeodomain finger protein 6 (PHF6), which possesses two chromatin-binding zinc finger domains and has been implicated in the Börjeson-Forssman-Lehmann X-linked intellectual disability syndrome (BFLS), T-cell acute lymphoblastic leukemia (T-ALL), and acute myeloid leukemia (AML) [9-11].

\subsection{Structure and Expression Pattern of PHF6}

The PHF6 (Gene ID: 84295) gene is located on the X chromosome, consists of 11 exons, and is transcribed into a $4.5 \mathrm{~kb}$ mRNA (see Figure 1A). Exons 2-10 encode a 365 amino acid (41 kDa) protein (Uniprot: Q8IWS0) (see Figure 1B), while exons 1 and 11 comprise the 5' and 3' untranslated regions (UTRs), respectively. Two mRNA isoforms exist in humans, with the second incorporating intron 10 to increase the size of the 3' UTR [9]. A third isoform is predicted to encode a truncated 312 amino acid version of the PHF6 protein, but its existence has not been confirmed experimentally [12]. The PHF6 protein is highly conserved among vertebrates, with $97.5 \%$ amino acid identity between humans and mice. Invertebrates do not have a PHF6 homolog. Structurally, the most prominent features of PHF6 are its two nearly identical zinc finger domains (ZaP1: aa 14-134; ZaP2: aa 209-332) that are derived from a PZP motif [13]. PZP motifs consist of a PHD domain, followed by a zinc knuckle, followed by an atypical $\mathrm{PHD}$ domain, however each zinc finger domain of PHF6 is a degenerate version of this structure as they consist only of the zinc knuckle and the atypical PHD (ZaP) [14]. PHF6 also contains two nuclear localization sequences (NLS1: aa 13-16; NLS2: aa 129-133) and a nucleolar localization sequence (NoLS: 157-169), with the localization of PHF6 to the nucleus and nucleolus having been confirmed by immunocytochemistry, subcellular fractionation, and mass spectrometry-based identifications [9,14-18].

To date, no Phf6 animal knockout models have been published and few studies record its gene expression patterns during embryonic and postnatal mouse development. In mice, Phf6 expression has been observed to be ubiquitous, with particularly high expression in the brain and central nervous system (CNS) throughout embryonic development, and more moderate expression during post-natal development and in adult tissues [19]. Particularly high PHF6 expression is observed in the cortical plate and intermediate zone at E14.5, as well as the ventricular and subventricular zones by E16.5 [20]. Phf6 is also highly expressed in other embryonic tissues, including the anterior pituitary at E12.5, nasal processes from E9.5 to E12.5, pharyngeal arches at E9.5, and limb buds at E12.5. In another study, Phf6 expression was elevated in murine T-cell lymphoma, supporting observations of high PHF6 expression in human adult B- and T-lymphoid cells $[11,15]$. Thus, collectively, these expression studies are indicative of a potential role for PHF6 during both neurogenesis and hematopoiesis. 

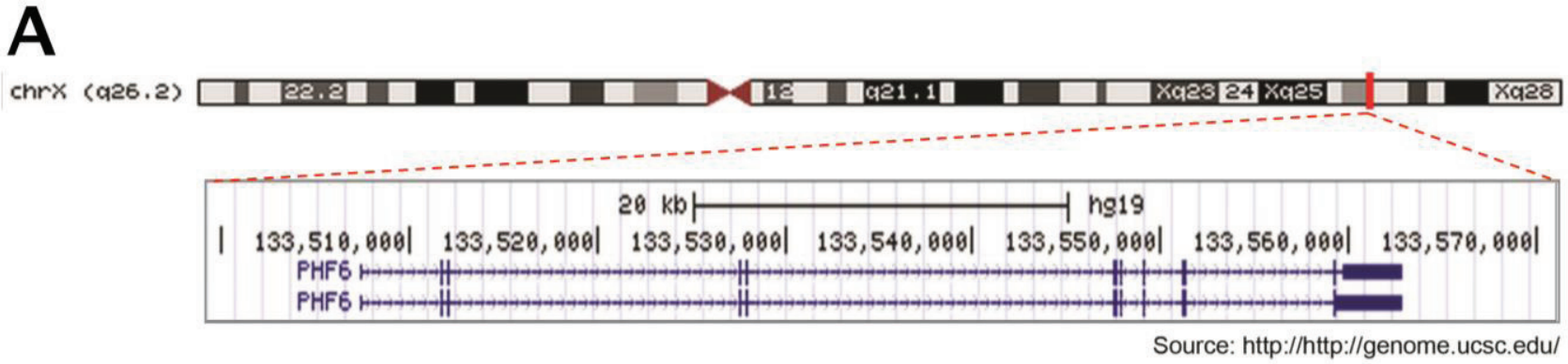

B

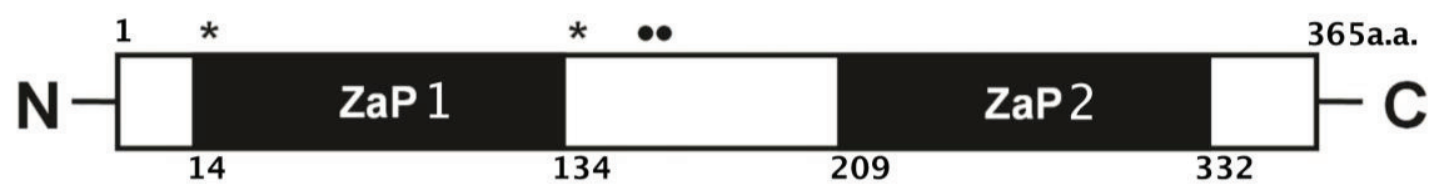

Figure 1. PHF6 gene and protein domain structures. (A) The PHF6 gene contains 11 exons and is located on the X chromosome. Source: UCSC Genome Browser [21]. (B) The gene encodes a protein of 365 amino acids with two ZaP (zinc knuckle, atypical PHD) domains and localization signals for the nucleus $\left({ }^{*}\right)$ and nucleolus $(\bullet)$.

\subsection{Regulation of PHF6 Transcripts}

The epigenetic mechanisms that regulate PHF6 transcription have not been well characterized aside from the identification of a NOTCH1 binding site and DNA methylation sites in the PHF6 promoter [22,23]. Post-transcriptionally, PHF6 mRNA is targeted by as many as 25 microRNAs, including miR-20a, miR-26a, miR-128, and miR-574 [20,24,25]. Franzoni et al. recently described that miR-128, which has three binding sites in the Phf6 3' UTR, is essential for mediating the switch between neuronal migration and neurite outgrowth by silencing $P h f 6$ in upper level cortical neurons [20]. Indeed the downregulation of Phf6 that occurs in these cortical layers during development was inversely correlated with an increase in the expression levels of miR-128. Interestingly, miR-128 is also oncogenically expressed in tumours arising from non-neuronal tissue, including T-ALL, where PHF6 was confirmed as a target [25].

\section{Consequences of Germline Mutations of PHF6}

\subsection{Börjeson-Forssman-Lehmann Syndrome (BFLS)}

The BFLS phenotype was first reported a half century ago and the multiple variable aspects of the phenotype have been well described in the literature [26-30]. The majority of BFLS cases occur in males who display developmental delay within their first year after birth, with mild to severe intellectual disability becoming apparent during childhood and adolescence [27,28]. Additional features of the BFLS phenotype include large ears, coarse facial features (e.g., deep set eyes), long tapered fingers, syndactyly and shortening of the toes, gynecomastia, truncal obesity, hypogonadism, hypotonia, and feeding problems during infancy. Some features are present at birth (e.g., hypogonadism), however other aspects of the phenotype present themselves during childhood and adolescence (e.g., coarse facial features, truncal obesity). Gynecomastia in particular emerges during adolescence, although it is unclear if it is 
caused by breast tissue hyperplasia or lipomastia [29]. Less common features of BFLS include microcephaly/macrocephaly, short stature, epilepsy, cleft lip and palate, hearing impairment, and hypopituitarism [28]. Two independent probands have also been diagnosed with bone marrow cancers, including Hodgkin's lymphoma and T-ALL [29,31]. Female carriers within BFLS families typically display mild, if any, symptoms, with at least one isolated female patient expressing a de novo PHF6 mutation having been diagnosed with BFLS marked by mild intellectual disability [32].

While BFLS was long known to be X-linked, having been previously mapped to the Xq26-27 chromosomal region, it was not until 2002 that PHF6 mutations were identified as its cause [9,33-35]. These mutations include missense mutations, nonsense mutations, and deletions (see Table 1). These mutations are distributed across the entire PHF6 gene, suggesting that the associated BFLS phenotypes arise from a loss of PHF6 function, however attempts to identify genotype-phenotype correlations between specific PHF6 mutations and the severity of intellectual disability have not been successful $[29,30]$. To date, no other gene mutations are known to cause BFLS, however not all BFLS patients have an identified PHF6 mutation. In one cohort, for instance, PHF6 mutations were only identified in 5/25 patients, indicating that there could be additional BFLS loci, or more likely, that the clinical diagnosis of BFLS overlaps with other syndromes [32]. In this regard, many X-linked intellectual disability syndromes (e.g., Coffin-Lowry syndrome, Klinefelter syndrome, Prader-Willi syndrome, Wilson-Turner syndrome) share overlapping phenotypes with BFLS such as gynecomastia, obesity, hypotonia, hypogonadism, or digit abnormalities [28,36].

\subsection{Coffin-Siris syndrome}

First described in 1970, Coffin-Siris syndrome (reviewed by [37,38]) is an intellectual disability disorder that is caused by mutations in genes encoding individual subunits of the BAF (BRG1/BRM-associated factor) complex, including ARID1A, ARID1B, SMARCA2, SMARCA4 (BRG1), SMARCB1 (INI1), and SMARCE1 (BAF57) [39,40]. Interestingly, several recent studies describe female patients expressing de novo PHF6 mutations that exhibit more severe intellectual disability than female BFLS carriers, overlapping more closely with Coffin-Siris syndrome than with features of classical BFLS [30,41-44]. Distinguishing features of this newly described phenotype include sparse hair, deep set eyes, hypoplasia of the fifth digit, linear skin hyperpigmentation, and dental abnormalities [44]. Unlike male BFLS patients, these females do not display truncal obesity and syndactyly occurs between the third and fifth toes, rather than between the second and third toes [42,44]. Notably, de novo PHF6 mutations in females primarily consist of deletions or frameshift mutations (see Table 1) in comparison to male BFLS patients or female carriers, which more commonly express point mutations. Furthermore, it is tantalizing to speculate that these more deleterious mutations might be lethal in males.

Female patients with de novo PHF6 mutations are nearly indistinguishable from Coffin-Siris syndrome patients during early infancy, but develop a more distinct phenotype as they age, such as the display of linear skin hyperpigmentation, which does not occur in Coffin-Siris syndrome patients [30,41]. Interestingly, females that lack linear skin hyperpigmentation exhibit a phenotype that more closely resembles classical BFLS than the Coffin-Siris-like phenotype. Indeed, Zweier et al. argue that functional mosaicism from variable rates of skewed X-chromosome inactivation in different tissues drives the Coffin-Siris-like phenotype [30]. In this regard, every documented case of a female patient expressing a de novo PHF6 mutation has presented with skewed X-chromosome inactivation 
(in peripheral blood) of $93 \%$ or higher, yet they present with a severe phenotype [30]. However, analysis of fibroblast cells in some Coffin-Siris-like patients has demonstrated variable X-inactivation (58\%-83\%) suggesting that reduced X-inactivation skewing in other tissues is what contributes to the phenotypic differences [42]. Consistent with this idea, there is no correlation with the level of skewing in peripheral blood cells in BFLS carriers with or without a phenotype $[29,42,43]$. Therefore, whether or not female patients expressing a PHF6 mutation develop BFLS or the Coffin-Siris-like phenotype may depend upon the type of mutation (deletion vs. point mutation) and on the extent to which skewed $\mathrm{X}$-chromosome inactivation occurs in different tissues.

Table 1. Summary of germline PHF6 mutations.

\begin{tabular}{|c|c|c|c|c|c|c|c|}
\hline Gender & Nucleotide Change & $\begin{array}{l}\text { Amino Acid } \\
\text { Change }\end{array}$ & $\begin{array}{l}\text { Type of } \\
\text { Mutation }\end{array}$ & $\begin{array}{l}\text { Location of } \\
\text { Mutation }\end{array}$ & Cancer & $\begin{array}{l}\text { Isolated }{ }^{3 /} \\
\text { De novo }\end{array}$ & Reference \\
\hline M & c. $2 \mathrm{~T}>\mathrm{C}$ & p.M1T & Missense & Exon 2 & & & {$[9]$} \\
\hline M & c. $2 \mathrm{~T}>\mathrm{C}$ & p.M1T & Missense & Exon 2 & & & {$[32]$} \\
\hline M & c. $134 \mathrm{G}>\mathrm{A}$ & p.C45Y & Missense & Exon 2 & & & {$[9]$} \\
\hline M & c. $134 \mathrm{G}>\mathrm{A}$ & p.C45Y & Missense & Exon 2 & & Isolated & [9] \\
\hline M & c. $266 \mathrm{G}>\mathrm{T}$ & p.G89V & Missense & Exon 4 & & & {$[45]$} \\
\hline M & c. $296 \mathrm{G}>\mathrm{T}$ & p.C99F & Missense & Exon 4 & & Isolated & {$[9]$} \\
\hline $\mathrm{M}, \mathrm{F}$ & c. $686 \mathrm{~A}>\mathrm{G}$ & p.H229R & Missense & Exon 7 & & & [9] \\
\hline M & c. $700 \mathrm{~A}>\mathrm{G}$ & p.K234E & Missense & Exon 7 & & & [9] \\
\hline M & c. $769 \mathrm{~A}>\mathrm{G}$ & p.R257G & Missense & Exon 8 & & & [9] \\
\hline M & c. $769 \mathrm{~A}>\mathrm{G}$ & p.R257G & Missense & Exon 8 & $\mathrm{Yes}^{2}$ & Isolated & {$[16]$} \\
\hline M & c. $940 \mathrm{~A}>\mathrm{G}$ & p.I314V & Missense & Exon 9 & & & {$[32]$} \\
\hline M & c. $22 \mathrm{~A}>\mathrm{T}$ & p.K $8^{*}$ & Nonsense & Exon 2 & & & {$[9]$} \\
\hline $\mathrm{F}$ & c. $955 \mathrm{C}>\mathrm{T}$ & p.R319* & Nonsense & Exon 9 & & De novo & {$[42]$} \\
\hline M & c. $1024 \mathrm{C}>\mathrm{T}$ & p.R342* & Nonsense & Exon 10 & & De novo & {$[26,28]$} \\
\hline M & c. $1024 \mathrm{C}>\mathrm{T}$ & p.R342* & Nonsense & Exon 10 & & & [9] \\
\hline M & c. $1024 \mathrm{C}>\mathrm{T}$ & p.R342* & Nonsense & Exon 10 & & & [9] \\
\hline M & c. $1024 \mathrm{C}>\mathrm{T}$ & p.R342* & Nonsense & Exon 10 & & & [9] \\
\hline M & c. $1024 \mathrm{C}>\mathrm{T}$ & p.R342* & Nonsense & Exon 10 & $\mathrm{Yes}^{3}$ & & {$[31]$} \\
\hline $\mathrm{F}$ & c. $27 \mathrm{dupA}$ & p.G10fs*21 & Frameshift & Exon 2 & & De novo & {$[32]$} \\
\hline M & IVS2-8A>G & $\mathrm{M} 46 \mathrm{fs} \Delta \mathrm{exon} 3$ & Frameshift & Exon 3 & & & {$[16]$} \\
\hline $\mathrm{F}$ & c. $677 \mathrm{delG}$ & p.G226fsE*53 & Frameshift & Exon 7 & & De novo & [41] \\
\hline $\mathrm{F}$ & c. $914 \mathrm{G}>\mathrm{T}$ & p.C305F & Frameshift & Exon 9 & & De novo & {$[41]$} \\
\hline $\mathrm{F}$ & & & Duplication & Exons 4-5 & & De novo & {$[42]$} \\
\hline $\mathrm{F}$ & & & Duplication & Exons 4-5 & & De novo & {$[42]$} \\
\hline $\mathrm{F}$ & $6 \mathrm{~kb}$ deletion & & Deletion & Exons 4-5 & & De novo & {$[42]$} \\
\hline F & $100 \mathrm{~kb}$ deletion & & Deletion & Exons 6-10 & & De novo & {$[44]$} \\
\hline $\mathrm{F}$ & $15 \mathrm{~kb}$ deletion & & Deletion & Exons 9-11 & & De novo & {$[43]$} \\
\hline M & c.999-1001 delTGA & p.D333del & Deletion & Exon 10 & & & {$[46]$} \\
\hline M & c.999-1001 delTGA & p.D333del & Deletion & Exon 10 & & & {$[26,28]$} \\
\hline $\mathrm{F}$ & Entire gene deleted & & Deletion & Whole gene & & De novo & {$[42]$} \\
\hline $\mathrm{F}$ & $270 \mathrm{~kb}$ deletion & & Deletion & Whole gene & & Isolated & {$[44]$} \\
\hline
\end{tabular}

${ }^{1}$ Isolated refers to instances where the parents have not been screened for PHF6 mutations.

${ }^{2}$ Hodgkin's lymphoma

${ }^{3}$ T-cell acute lymphoblastic leukemia 


\section{Consequences of Somatic Mutations of PHF6}

\subsection{T-Cell Acute Lymphoblastic Leukemia (T-ALL)}

Somatic PHF6 mutations in human tumours were first described for T-ALL patients [10,31]. Van Vlierberghe and colleagues reported PHF6 mutations in $16 \%$ of pediatric and $38 \%$ of adult subjects. In four additional studies, other groups have identified T-ALL-related PHF6 mutation frequencies varying from 5\% to 40\% within each cohort [47-50]. While Van Vlierberghe et al. reported a significantly higher incidence of PHF6 mutations among males, gender differences were not observed in these later studies. In contrast to male BFLS patient mutations, which are primarily missense, neoplastic PHF6 mutations overwhelmingly consist of deletions, frameshifts, nonsense mutations, or missense mutations that target zinc ion stabilizing residues in the second $\mathrm{ZaP}$ domain (see Table 2). Collectively, these findings suggest that PHF6 is a tumour suppressor and that these mutations result in a loss of function, consistent with silencing of the PHF6 promoter by DNA methylation in some T-ALL tumours [23].

T-ALL arises from developmentally arrested immature T-cells that express one or more mutations to bypass key developmental checkpoints (i.e. $\beta$ selection, $-/+$ selection) during thymocyte maturation [51]. Many of the mutations contributing to T-ALL involve oncogenic translocation events at the T-cell receptor (TCR) gene loci and are categorized within two groups: (i) those that initiate oncogenesis and define the molecular-genetic subtype of the tumour, and (ii) mutations that are recurrent [52]. Major T-ALL subtypes are defined by aberrant oncogenic activation or chromosomal translocation events in genes coding for bHLH proteins (e.g., TAL1), LMO proteins (e.g., LMO1), homeobox proteins (e.g., TLX1, TLX3), or proto-oncogenes (e.g., c-MYB), while recurrent mutations target cell signalling pathways (e.g., NOTCH1, signal transduction), cell cycle regulatory mechanisms, and tumour suppressors (i.e. for inactivation) [52]. Interestingly, PHF6 mutations are associated with tumours expressing the TLX1 and TLX3 oncogenes [10]. Consistent with this observation, PHF6 is highly expressed in DP cells, the stage at which $T L X 1$-induced tumours most commonly experience developmental arrest [10,53]. Moreover, PHF6 has also been demonstrated to be a direct target of TLX1-mediated repression [54]. PHF6 mutations are also co-expressed with JAK1 mutations, SET-NUP214 translocations, and activating NOTCH1 mutations, which occur in over half of all T-ALL patients $[48,50,55]$.

\subsection{Acute Myeloid Leukemia (AML)}

PHF6 mutations have also been identified in AML patients (see Table 2) [11]. AML is a heterogeneous cancer that develops in multiple progenitor cell types of the myeloid lineage. Recent profiling of the AML cancer genome with next-generation sequencing has demonstrated that most AML mutations are recurrent, consisting primarily of chromosomal translocation events at specific loci and targeted mutations among a group of 23 genes, including epigenetic regulators such as DNMT3A, TET2, and RUNX1 [8]. Van Vlierberghe et al. found PHF6 mutations in 10/353 patients. Similar to T-ALL, PHF6 mutations primarily consisted of deletions, frameshifts, nonsense mutations and missense mutations targeting zinc ion-stabilizing residues from the second ZaP domain. Additional AML screens by other groups found PHF6 mutations in 3\% of screened tumours [8]. Additionally, PHF6 mutations correlated with reduced overall survival in adult patients and were observed to be co-expressed with 
RUNX1 mutations $[8,56]$. As of yet, tumours expressing PHF6 mutations have not been correlated with any specific myeloid progenitor cell type, however PHF6 expression levels were observed to be higher in hematopoietic stem cells and megakaryocyte/erythroid progenitors than in common myeloid progenitors or granulocyte/macrophage progenitors [11].

\subsection{PHF6 Loss-of-Function in Other Neoplasias}

Isolated cases of loss-of-function PHF6 mutations in chronic myeloid leukemia (CML) and hepatocellular carcinoma patient tumours have also been reported [49,57]. Interestingly, shRNA-mediated knockdown of Phf6 in a murine B-cell acute lymphoblastic leukemia (B-ALL) model was observed to significantly reduce the rates of tumour proliferation, in contrast to both T-ALL and AML models, where the loss of Phf6 correlates with enhanced tumour progression [24,58]. Consistent with the B-ALL model, PHF6 knockdown in a HeLa cell model led to a reduction in rates of cellular proliferation, accompanied by a cell cycle delay at G2/M [59]. Thus, the downstream functions of PHF6 leading to tumour suppression in specific cell or tissue types (e.g., lymphoid and myeloid) are not necessarily limited to proliferative or cell cycle regulatory processes. Rather, PHF6 likely participates in additional development regulatory networks that are context-dependent and tissue-specific, with the tumorigenic outcome being influenced by the presence of additional oncogenic mutations. This pathogenic model is analogous to the example provided by BCL11B in developing thymocytes, in which the loss of BCL11B on its own induces massive apoptosis during $\beta$-selection, yet also favours T-ALL progression when lost in combination with other oncogenically favourable events $[54,60]$. 
Table 2. Summary of cancer-related PHF6 mutations.

\begin{tabular}{|c|c|c|c|c|c|c|}
\hline Gender & Nucleotide Change & Amino Acid Change & Type of Mutation & $\begin{array}{c}\text { Location of } \\
\text { Mutation } \\
\end{array}$ & Cancer $^{1}$ & Reference \\
\hline $\mathrm{F}$ & c.90_91insCCCG & p.L31PfsX6 & Insertion/Deletion & Exon 2 & T-ALL & [49] \\
\hline M & & p.G10fs & Frameshift & Exon 2 & T-ALL & {$[10]$} \\
\hline M & & p.A41fs & Frameshift & Exon 2 & T-ALL & {$[10]$} \\
\hline M & & p.H44fs & Frameshift & Exon 2 & T-ALL & {$[10]$} \\
\hline $\mathrm{F}$ & c.76-95del20+insTTGG & p.P26fs & Frameshift & Exon 2 & T-ALL & {$[48]$} \\
\hline M & & p.Y105fs & Frameshift & Exon 3 & T-ALL & {$[10]$} \\
\hline M & c.267_268insTTAGGACC & p.A90LfsX10 & Insertion/Deletion & Exon 4 & T-ALL & [49] \\
\hline M & & p.G122X & Nonsense & Exon 4 & T-ALL & {$[10]$} \\
\hline M & & p.R116X & Nonsense & Exon 4 & T-ALL & {$[10]$} \\
\hline M & & p.T98fs & Frameshift & Exon 4 & T-ALL & {$[10]$} \\
\hline $\mathrm{F}$ & c. $289 \mathrm{~A}>\mathrm{T}$ & p.K97X & Nonsense & Exon 4 & T-ALL & {$[48]$} \\
\hline M & & p.H135fs & Frameshift & Exon 5 & T-ALL & {$[10]$} \\
\hline $\mathrm{F}$ & & p.F172fs & Frameshift & Exon 6 & T-ALL & {$[10]$} \\
\hline M & & p.R225X & Nonsense & Exon 6 & T-ALL & {$[10]$} \\
\hline M & & p.S158fs & Frameshift & Exon 6 & T-ALL & {$[10]$} \\
\hline M & & p.S191fs & Frameshift & Exon 6 & T-ALL & {$[10]$} \\
\hline M & c.525_526delGT & p.S176fs & Frameshift & Exon 6 & T-ALL & {$[48]$} \\
\hline M & c. $673 \mathrm{C}>\mathrm{T}$ & p.R225X & Nonsense & Exon 7 & T-ALL & [49] \\
\hline M & c.653_667delGGGAGGAAGAAAATGinsCCCTTTAAAGGGA & p.G218AfsX & Insertion/Deletion & Exon 7 & T-ALL & [49] \\
\hline M & & p.K235X & Nonsense & Exon 7 & T-ALL & {$[10]$} \\
\hline M & & p.C215Y & Missense & Exon 7 & T-ALL & {$[10]$} \\
\hline M & & p.G263fs & Frameshift & Exon 8 & T-ALL & {$[10]$} \\
\hline M & c.735M736dupTT & p.S246FfsX34 & Duplication & Exon 8 & T-ALL & [49] \\
\hline M & & p.K273X & Nonsense & Exon 8 & T-ALL & {$[10]$} \\
\hline M & & p.C280Y & Missense & Exon 8 & T-ALL & {$[10]$} \\
\hline M & & p.R257X & Nonsense & Exon 8 & T-ALL & {$[10]$} \\
\hline M & c. $820 \mathrm{~T}>\mathrm{C}$ & p.R274X & Nonsense & Exon 8 & T-ALL & {$[10]$} \\
\hline
\end{tabular}


Table 2. Cont.

\begin{tabular}{|c|c|c|c|c|c|c|}
\hline Gender & Nucleotide Change & Amino Acid Change & Type of Mutation & $\begin{array}{c}\text { Location of } \\
\text { Mutation }\end{array}$ & Cancer $^{1}$ & Reference \\
\hline M & c. $808 \mathrm{C}>\mathrm{T}$ & p.Q270X & Nonsense & Exon 8 & T-ALL & [48] \\
\hline M & c. $823 \mathrm{G}>\mathrm{A}$ & p.G275R & Missense & Exon 8 & T-ALL & {$[48]$} \\
\hline M & c.779insCGGGAGGATCC & p.D262fs & Frameshift & Exon 8 & T-ALL & [48] \\
\hline M & & p.S320X & Nonsense & Exon 9 & T-ALL & {$[10]$} \\
\hline M & c. $903 \mathrm{C}>\mathrm{A}$ & p.Y301X & Nonsense & Exon 9 & T-ALL & [49] \\
\hline M & & p.Y303fs & Frameshift & Exon 9 & T-ALL & {$[10]$} \\
\hline M & & p.C283R & Missense & Exon 9 & T-ALL & {$[10]$} \\
\hline M & & p.T300A & Missense & Exon 9 & T-ALL & {$[10]$} \\
\hline M & & p.A311P & Missense & Exon 9 & T-ALL & {$[10]$} \\
\hline M & & p.Y303X & Nonsense & Exon 9 & T-ALL & {$[10]$} \\
\hline M & c.933_934insT & p.A311X & Nonsense & Exon 9 & T-ALL & [48] \\
\hline M & c. $835 \mathrm{delA}$ & p.K279fs & Frameshift & Exon 9 & T-ALL & {$[48]$} \\
\hline M & c. $1024 \mathrm{C}>\mathrm{T}$ & p.R342* & Nonsense & Exon 10 & T-ALL & [31] \\
\hline M & & p.D333fs & Frameshift & Exon 10 & T-ALL & {$[10]$} \\
\hline M & c. $986 \mathrm{~A}>\mathrm{G}$ & p.H329R & Missense & Exon 10 & T-ALL & {$[10]$} \\
\hline M & c. $973 \mathrm{~T}>\mathrm{C}$ & p.Y325H & Missense & Exon 10 & T-ALL & [48] \\
\hline M & & p.C215Y & Missense & Exon 7 & T-ALL & {$[10]$} \\
\hline M & & p.C28fs & Frameshift & Exon 2 & T-ALL & {$[10]$} \\
\hline $\mathrm{F}$ & c. $968+1 \mathrm{G}>\mathrm{A}$ & Undetermined & Non-coding & Intron 9 & T-ALL & [49] \\
\hline M & c.968+2T_968+5GdelTAAG & Undetermined & Non-coding & Intron 9 & T-ALL & [49] \\
\hline M & $0.55 \mathrm{Mb}$ deleted & Absent & Deletion & $\mathrm{n} / \mathrm{a}$ & T-ALL & {$[10]$} \\
\hline M & $0.23 \mathrm{Mb}$ deleted & Absent & Deletion & $\mathrm{n} / \mathrm{a}$ & T-ALL & {$[10]$} \\
\hline M & $1.50 \mathrm{Mb}$ deleted & Absent & Deletion & $\mathrm{n} / \mathrm{a}$ & T-ALL & [10] \\
\hline M & $0.27 \mathrm{Mb}$ deleted & Absent & Deletion & $\mathrm{n} / \mathrm{a}$ & T-ALL & [10] \\
\hline M & $1.90 \mathrm{Mb}$ deleted & Absent & Deletion & $\mathrm{n} / \mathrm{a}$ & T-ALL & {$[10]$} \\
\hline M & $0.20 \mathrm{Mb}$ deleted & Absent & Deletion & $\mathrm{n} / \mathrm{a}$ & T-ALL & {$[10]$} \\
\hline M & $0.08 \mathrm{Mb}$ deleted & Absent & Deletion & $\mathrm{n} / \mathrm{a}$ & T-ALL & [10] \\
\hline
\end{tabular}


Table 2. Cont.

\begin{tabular}{|c|c|c|c|c|c|c|}
\hline Gender & Nucleotide Change & Amino Acid Change & Type of Mutation & $\begin{array}{c}\text { Location of } \\
\text { Mutation }\end{array}$ & Cancer1 & Reference \\
\hline M & $0.11 \mathrm{Mb}$ deleted & Absent & Deletion & $\mathrm{n} / \mathrm{a}$ & T-ALL & {$[10]$} \\
\hline M & & p.C20fs & Frameshift & Exon 2 & AML & {$[11]$} \\
\hline M & & p.A40G & Missense & Exon 2 & AML & [11] \\
\hline $\mathrm{F}$ & & p.N171fs & Frameshift & Exon 6 & AML & {$[11]$} \\
\hline M & & p.P200fs & Frameshift & Exon 7 & AML & {$[11]$} \\
\hline M & & p.R274X & Nonsense & Exon 8 & AML & {$[11]$} \\
\hline M & & p.R335fs & Frameshift & Exon 9 & AML & [11] \\
\hline M & & p.H302Y & Missense & Exon 9 & AML & [11] \\
\hline M & & p.R319X & Nonsense & Exon 9 & AML & {$[11]$} \\
\hline M & & p.H329L & Missense & Exon 10 & AML & {$[11]$} \\
\hline M & & p.R342X & Nonsense & Exon 10 & AML & {$[11]$} \\
\hline M & c.27dupA & p.K9RfsX12 & Duplication & Exon 2 & AML & [49] \\
\hline M & c.83_101delGTGGACAGTTACTAATATCinsAT & P.C28YfsX2 & Insertion/Deletion & Exon 2 & AML & [49] \\
\hline M & c. $769 \mathrm{~A}>\mathrm{G}$ & p.R257G & Missense & Exon 8 & HA & {$[16]$} \\
\hline M & c. $673 \mathrm{C}>\mathrm{T}$ & p.R225X & Nonsense & Exon 7 & $\mathrm{HC}$ & [9] \\
\hline \multirow[t]{2}{*}{ M } & c. $665 \mathrm{C}>\mathrm{T}$ & p.A135V & Missense & Exon 5 & CML & [57] \\
\hline & & p.N137_E139del140f & & & & \\
\hline M & c.670-679del10 & sX142 & Frameshift & Exon 5 & CML & [57] \\
\hline M & c.895-896delTG & p.C212WfsX222 & Frameshift & Exon 7 & CML & [57] \\
\hline
\end{tabular}

${ }^{1} \mathrm{HA}=$ Hodgkin's lymphoma; $\mathrm{HC}=$ Hepatocellular carcinoma; $\mathrm{CML}=$ Chronic myeloid leukemia 


\section{Delineating the Functional Interactions of PHF6}

Until relatively recently, the role of PHF6 was categorized based on its homology with chromatin remodelling proteins, however several recent studies have shed an early light upon how its molecular responsibilities may contribute to the developmental processes of neurogenesis and hematopoiesis; activities that become compromised during development and/or in cancer. These studies included structural characterization of the PHF6 zinc finger domain, nuclear and nucleolar localization studies, the identification of PHF6-containing protein complexes, and reports of putative phosphorylation sites.

\subsection{Functional Analysis of the Conserved Motifs within PHF6}

In humans, $\mathrm{PZP} / \mathrm{ZaP}$ domains are primarily found in proteins that participate in transcriptional regulation or changes to chromatin structure (e.g., histone acetylation, methylation, demethylation) (see Table 3) [14]. Canonical PHD domains are Cys4-His-Cys3 type zinc fingers that chelate two zinc ions and participate in protein-protein interactions with post-translationally modified and unmodified histone H3 or H4 histone tails [61-67]. Conversely, the atypical PHD of the ZaP domain is a Cys4-His-Cys2-His type zinc finger, which does not bind histones [68,69]. Moreover, a ZaP domain carries a net positive charge that is greater than a PHD domain, suggestive of an interaction with a negatively charged substrate [68]. Indeed, NMR solution and crystal structures that have recently been derived for the BRPF2 and the PHF6 ZaP2 domains indicate that this structure is able to bind double-stranded DNA templates in a sequence-independent manner, however the ability of the ZaP domain to interact with additional nucleic acid structures (e.g., RNA) has so far not yet been investigated $[68,69]$. Interestingly, a recent high throughput screen identified PHF6 and other ZaP-containing proteins amongst a list of putative mRNA-interactors [70]. Moreover, the PHF6 ZaP1 domain was observed to have nucleolar localization in the absence of the NoLS and a single point mutation of a zinc ion stabilizing residue (C99F) within ZAP1 resulted in the ablation of PHF6 nucleolar localization [59]. In another study, the loss of both NLSs and the NoLS resulted in the nuclear, but not nucleolar, localization of PHF6 [15]. Taken together, these data suggest that additional interactions may be necessary to ensure the recruitment of PHF6 to the nucleoplasm and nucleolus.

\subsection{PHF6 Interacting Partners}

\subsubsection{Nucleosome Remodelling and Deacetylation (NuRD) complex}

We have previously demonstrated PHF6 to endogenously co-purify with multiple constituents of the NuRD chromatin remodelling complex (CHD3/4, HDAC1, and RBBP4/7) (see Figure 2A), a transcriptional regulator with several gene targets that influence embryogenesis, oncogenesis, neurogenesis, and hematopoiesis [14,71-78]. The NuRD core complex has the ability to catalyze ATP-dependent nucleosome remodelling and histone deacetylation at its gene targets through its CHD and HDAC subunits, respectively $[79,80]$, but the transcriptional outcome of its targets is dependent upon its collective associations with other activators (e.g., P300) and repressors (e.g., LSD1) [81,82]. Several NuRD interactors also possess zinc finger domains with the ability to target the complex to gene targets through DNA sequence-specific interactions (e.g., IKAROS, SALL1, BCL11B), thus the binding affinity of PHF6 to dsDNA may favour the association of NuRD to a distinct subset of its gene targets [83-86]. 
Table 3. Functional comparison of human proteins expressing PZP motifs and/or ZaP domains.

\begin{tabular}{|c|c|c|c|c|c|}
\hline Protein & Uniprot Accession \# & Function & $\begin{array}{l}\text { PZP Motif or } \\
\text { ZaP Domain }\end{array}$ & Amino Acid Residues & Reference \\
\hline PHF6 & Q8IWS0 & Transcriptional regulation & $\mathrm{ZaP}(\mathrm{x} 2)$ & $14-134,209-332$ & {$[14,87]$} \\
\hline BRPF1 & P55201 & MOZ/MORF-dependent $\mathrm{H} 3$ acetylation & PZPM & $273-450$ & {$[88]$} \\
\hline BRPF2 & O95696 & MOZ/MORF-dependent $\mathrm{H} 3$ acetylation & PZPM & $214-391$ & {$[88]$} \\
\hline BRPF3 & Q9ULD4 & MOZ/MORF-dependent $\mathrm{H} 3$ acetylation & PZPM & $188-389$ & {$[88]$} \\
\hline G2E3 & Q7L622 & E3 ubiquitin-protein ligase & $\mathrm{ZaP}$ & $11-130$ & [89] \\
\hline JADE-1 & Q6IE81 & HBO1-dependent $\mathrm{H} 4$ acetylation & PZPM & $203-371$ & {$[88]$} \\
\hline JADE-2 & Q9NQC1 & HBO1-dependent $\mathrm{H} 4$ acetylation & PZPM & $199-367$ & {$[88]$} \\
\hline JADE-3 & Q92613 & HBO1-dependent $\mathrm{H} 4$ acetylation & PZPM & $200-368$ & {$[88]$} \\
\hline JMJD2A (KDM4A) & O75164 & H3K9/H3K36 demethylase & PZPM & $665-887$ & {$[90]$} \\
\hline JMJD2B (KDM4B) & O94953 & H3K9 demethylase & PZPM & $681-909$ & {$[90]$} \\
\hline JMJD2C (KDM4C) & Q9H3R0 & H3K9/H3K36 demethylase & PZPM & $642-867$ & {$[90]$} \\
\hline MLL1 (KMT2A) & Q03164 & H3K4 methyltransferase & PZPM & $1566-1980$ & [91] \\
\hline MLL2 (KMT2D) & O14686 & H3K4 methyltransferase & $\mathrm{ZaP}(\mathrm{x} 2)$ & $63-220,5029-5139$ & {$[92]$} \\
\hline MLL3 (KMT2C) & Q8NEZ4 & H3K4 methyltransferase & $\mathrm{ZaP}(\mathrm{x} 2)$ & $131-333,4399-4509$ & {$[93]$} \\
\hline MLL4 (KMT2B) & Q9UMN6 & H3K4 methyltransferase & PZPM & $1335-1688$ & {$[93]$} \\
\hline PHF7 & Q9BWX1 & Binds chromatin & $\mathrm{ZaP}$ & $30-147$ & [94] \\
\hline PHF11 & Q9UIL8 & Transcriptional regulation & $\mathrm{ZaP}$ & $42-162$ & [95] \\
\hline PHF14 & O94880 & Transcriptional regulation & PZPM & $319-501$ & {$[96]$} \\
\hline RAI1 & Q7Z5J4 & Transcriptional regulation & $\mathrm{ZaP}$ & $1780-1905$ & {$[97]$} \\
\hline TCF20 & Q9UGU0 & Transcriptional regulation & $\mathrm{ZaP}$ & $1789-1935$ & {$[98]$} \\
\hline
\end{tabular}


Many NuRD interactors (e.g.,SALL1, BCL11B, FOG-1) interface with the RBBP4 subunit through a conserved amino acid consensus sequence that is shared by PHF6 (aa 152-171) $[69,99,100]$. Indeed, Liu et al. confirmed a direct PHF6-RBBP4 interaction, and subsequently resolved the crystal structure to show that a PHF6 peptide (aa 162-170) peptide occupies a binding pocket located upon the surface of the RBBP4 $\beta$ propeller [69,101]. Interestingly, the PHF6 NoLS sequence overlaps with the RBBP4 binding domain, suggesting that these two activities may be mutually exclusive. Consistent with this assertion, the PHF6-NuRD/RBBP4 interaction was only found to occur in the nucleoplasm, and not within the nucleolus [14].

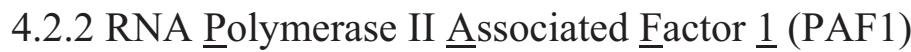

Aside from NuRD, Phf6 interacts with multiple subunits of the Pafl transcriptional elongation complex (Pafl, Leo1, Cdc73, Ctr9) (see Figure 2B), which is necessary to mediate proper neurogenesis in mice [87]. In this study, Phf6 and Pafl shRNA was electroporated into mouse cerebral cortices, resulting in impaired neuronal migration between E14 and E19. Using gene expression arrays, the authors identified Neuroglycan C/Chrondroitin Sulfate Proteoglycan 5 (NGC/CSPG5) as a commonly regulated gene target, and when the $N G C / C S P G 5$ transcript was electroporated into cortical tissue alongside Phf6 shRNA, the neuronal migration phenotype was rescued [87]. These findings are strikingly similar to those of Franzoni et al. who also ectopically expressed Phf6 to rescue neuronal migration defects that accompanied premature expression of miR-128 in the developing neocortices of mice [20]. Interestingly, Pafl also associates with the RNA Polymerase I machinery that is responsible for transcribing rRNA from rDNA genes, providing a potential means through which nucleolar Phf6 may be able to regulate rDNA gene expression [102].

\subsubsection{Additional Interactions}

In 2013, two independent studies identified an interaction between PHF6 and UBF (see Figure 2C) [59,87], an rDNA transcriptional activation factor that associates with the RNA Pol I pre-initiation complex [103,104]. In contrast to NGC/CSPG5, where PHF6 activates transcription, Wang et al. report that PHF6 represses rRNA transcription [59]. Moreover, they also report that a loss of PHF6 results in increased genomic instability at rDNA genes and a cell cycle delay at G2/M. While this was the first indication of a nucleolar function for PHF6, it has also been reported to interact with PRPF8 and SNRNP200, both constituents of the U4/U6-U5 tri-snRNP pre-mRNA splicing ribonucleoprotein complex [14]. 


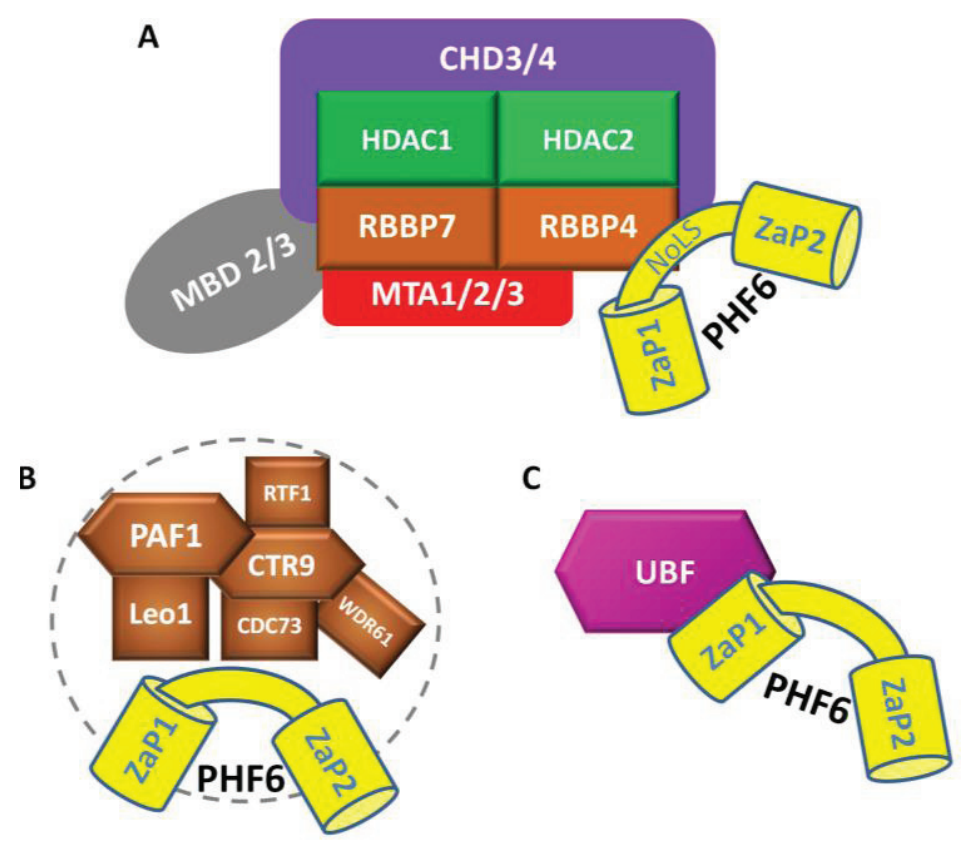

Figure 2. PHF6 interacting proteins. PHF6 associates with (A) the NuRD complex via a direct interaction between amino acid residues $162-170$ with the $\beta$ propeller surface of RBBP4; (B) the PAF1 complex; and (C) UBF, via its ZaP1 domain.

\subsection{PHF6 Is a Putative Phosphoprotein}

Aside from these direct studies investigating PHF6 interactions, several phosphoproteomic screens have identified PHF6 peptides, suggesting that it is regulated by phosphorylation [105-108]. In one study, the PHF6 T358 residue was identified as a target of the ATM DNA damage checkpoint kinase and the loss of PHF6 correlated with the accumulation of phosphorylated $\gamma \mathrm{H} 2 \mathrm{AX}[10,59,105]$. Interestingly, the R342X mutation associated with severe BFLS, and also identified in T-ALL and AML patients would truncate this phosphorylation site. While the functional importance of T358 phosphorylation remains to be determined, one possibility is that it serves as a checkpoint response to negatively regulate rDNA transcription (e.g., via RNA Pol I inhibition) [109].

Two other studies have identified the phosphorylation of three serine residues (S145; S154; and S155) during mitosis and in response to T-cell receptor signalling [106,107]. Interestingly, S145 phosphorylation is only ever observed in combination with phosphorylation at S155. Other high throughput screens indicate that S145 is a Polo-like kinase 1 (PLK1) target; consistent with its situation in a PLK1 consensus sequence; while phosphorylation at S155 provides a binding site for the polo binding domain of PLK1 (PBD); suggesting a mechanism whereby phosphorylation at S155 primes S145 for PLK1-mediated phosphorylation (see Figure 3) [108,110,111]. Indeed PLK1 inhibition reduces S145 phosphorylation with concomitant accumulation of singularly phosphorylated S155 peptide [108,112]. Interestingly, another screen identified S155 as a candidate substrate for CDK2 phosphorylation, and CDK2 inhibition interferes with the ability of PHF6 to localize to the nucleolus $[113,114]$. While the exact mechanism of this serine phosphorylation network within PHF6 requires more direct validation; it should be noted that PLK1 and CDK2 are highly active during S and $\mathrm{G}_{2}$ phase when nucleolar size and the rate of ribosome biogenesis is higher relative to $\mathrm{G}_{1}[115,116]$. Moreover, these phosphorylation sites are directly adjacent to the NoLS. Thus, we speculate that these 
phosphorylation events may promote shuttling of PHF6 between the nucleoplasm and nucleolus in response to external needs, such as compensation for the increased rates of rRNA synthesis that precede cytokinesis or following T-cell receptor activation during lymphogenesis.

A
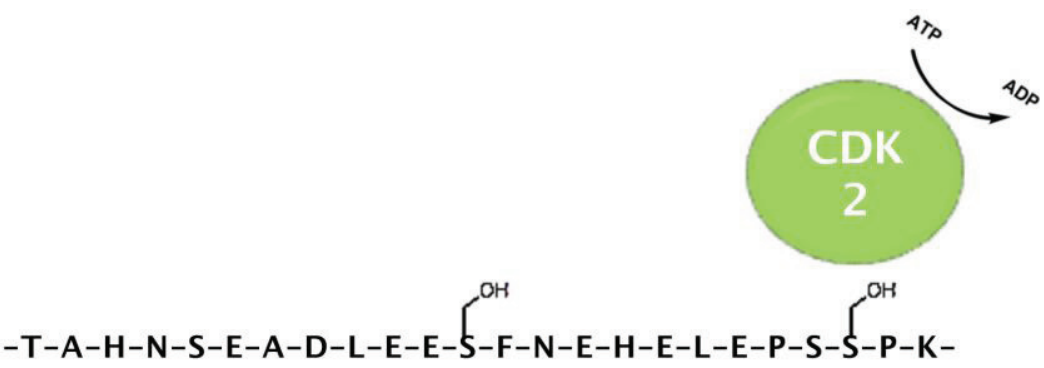

B

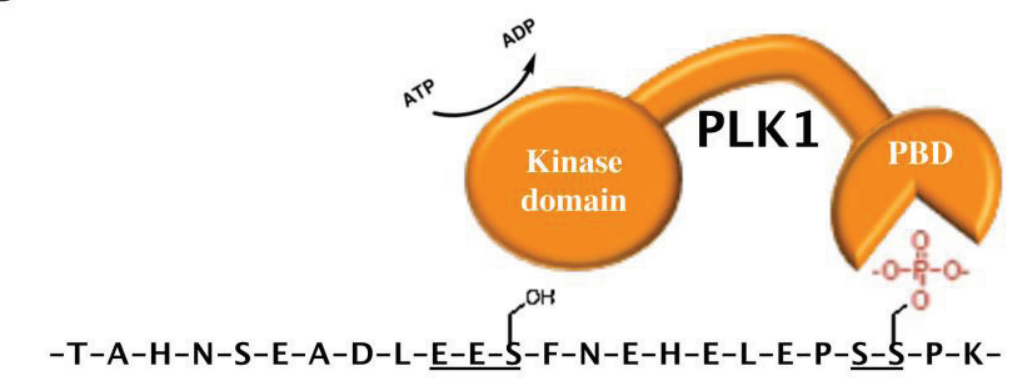

C

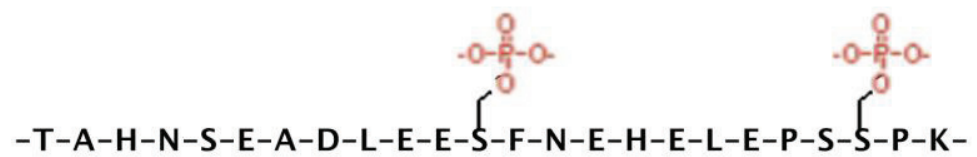

Figure 3. Model for the putative CDK2- and PLK1-dependent phosphorylation of PHF6. Large-scale proteomic studies identified PHF6 Ser-145, -154, and -155 as phosphorylated residues. The phosphorylation of these sites during mitosis or in response to T-cell receptor signalling likely occurs through a mechanism whereby (A) CDK2 phosphorylates Ser-155, allowing recognition by the Polo-binding domain (PBD) of PLK1 (B), which subsequently phosphorylates Ser-145, which is situated in a PLK1 consensus sequence (143-EESFNE-148), resulting in PHF6 becoming dually phosphorylated at these two sites $(\mathbf{C})$.

\section{Perspectives and Future Directions}

\subsection{Predicting Clinical Outcomes for Patients Expressing PHF6 Loss-of-Function}

The PHF6 protein is important for both faithful development and tumour suppression, yet only $6.5 \%$ of germline PHF6 mutations (see Table 1) are associated with cancer [29,31]. To explain why not all BFLS patients develop cancer, one consideration is that BFLS patients primarily have missense mutations that are likely functionally hypomorphic, whereas somatic PHF6 mutations causing cancer are frameshift, nonsense, or deletions that are in all likelihood functionally null. In addition, BFLS patients would still require a second mutation (e.g., $T L X 1$ ) within hematopoietic cells. Since female Coffin-Siris 
patients have a similar type of mutation to those individuals with T-ALL, they may be at greater risk for developing cancer. However, female patients with de novo germline deletions of PHF6 all have skewed $\mathrm{X}$-chromosome inactivation in the blood, which may explain why hematopoietic cancers have so far not been observed.

\subsection{Developmental Role of PHF6}

The PHF6 interactors identified to date suggest that PHF6 is a multifaceted regulator of transcription working with the NuRD chromatin remodelling complex (or UBF) to repress or activate transcriptional initiation, and with the PAF1 complex in controlling transcriptional elongation (Figure 4A). While these events may appear as disparate aspects of transcriptional control, they could be intimately linked. Indeed, many studies of IKAROS, a chromatin adaptor protein with DNA-binding zinc finger motifs, show that it can interact with both NuRD and the CDK9 catalytic subunit of positive-transcription elongation factor b (P-TEFb) [117-119]. Recent work has shown that IKAROS can recruit NuRD to specific target genes but it also interacts in a larger complex containing both NuRD and P-TEFb, in which IKAROS permits the transfer of protein phosphatase $1 \alpha(\mathrm{PP} 1 \alpha)$ to CDK9, which subsequently phosphorylates Ser-2 residues in the RNA pol II C-terminal domain (CTD), releasing RNA Pol II from promoter-proximal pausing to initiate elongation [119]. Thus, it is possible that PHF6 may interact within a NuRD-PAF1 supercomplex to promote productive elongation (see Figure 4B), although the existence of such a complex has yet to be defined.

In conducting future investigations to elucidate the transcriptional roles of such PHF6-containing complexes, it will be important to identify all PHF6 target genes through tissue-specific ChIP-Seq as a starting point to assess which PHF6 targets are PAF1 regulated, which ones require the recruitment of $\mathrm{NuRD}$, and which ones might utilize both complexes. Already, ChIP-Seq experiments for the NuRD constituents CHD4 and MBD3 indicate an enrichment of binding sites in gene bodies and well-defined peaks at transcriptional start site (TSS) regions [78,120]. Similarly, a recent PHF6 ChIP-Seq dataset generated from Jurkat cells presents binding sites that are predominantly located throughout gene bodies and within the proximal promoter [58]. Nonetheless, dissecting the different mechanisms of transcriptional regulation through the identification of target genes will allow for the better definition of relevant developmental pathways (e.g., neurogenesis, hematopoiesis) that become compromised in patients with BFLS, T-ALL, and/or AML. In this regard, the recent findings of a network whereby neurogenesis depends upon the timely expression of PHF6 to positively regulate NGC/CSPG5 (via PAF1) to ensure proper cortical neuron migration, and miR-128 to negatively regulate PHF6, which allows for subsequent neuronal maturation, represent the first clear model of a developmental role for PHF6 [20,87]. Moreover, PHF6 binding sites from the Jurkat ChIP-Seq dataset are found within genes responsible for cell cycle regulation, cell morphology mechanisms, and cell signalling pathways mediating axonal guidance [58]. Interestingly, PHF6 binds the NOTCH1 and RUNX1 promoters, genes that have mutations that are co-expressed with PHF6 mutations in T-ALL and AML, respectively $[8,48]$. Furthermore, the fact that NOTCH1 was itself found to bind the PHF6 promoter in a T-ALL cell line suggests that hematopoietically expressed PHF6 may participate within a feedback regulation network [22]. Therefore, carrying out these types of multidisciplinary approaches in primary tissues will be crucial to more fully understanding the functional roles of PHF6. 
B
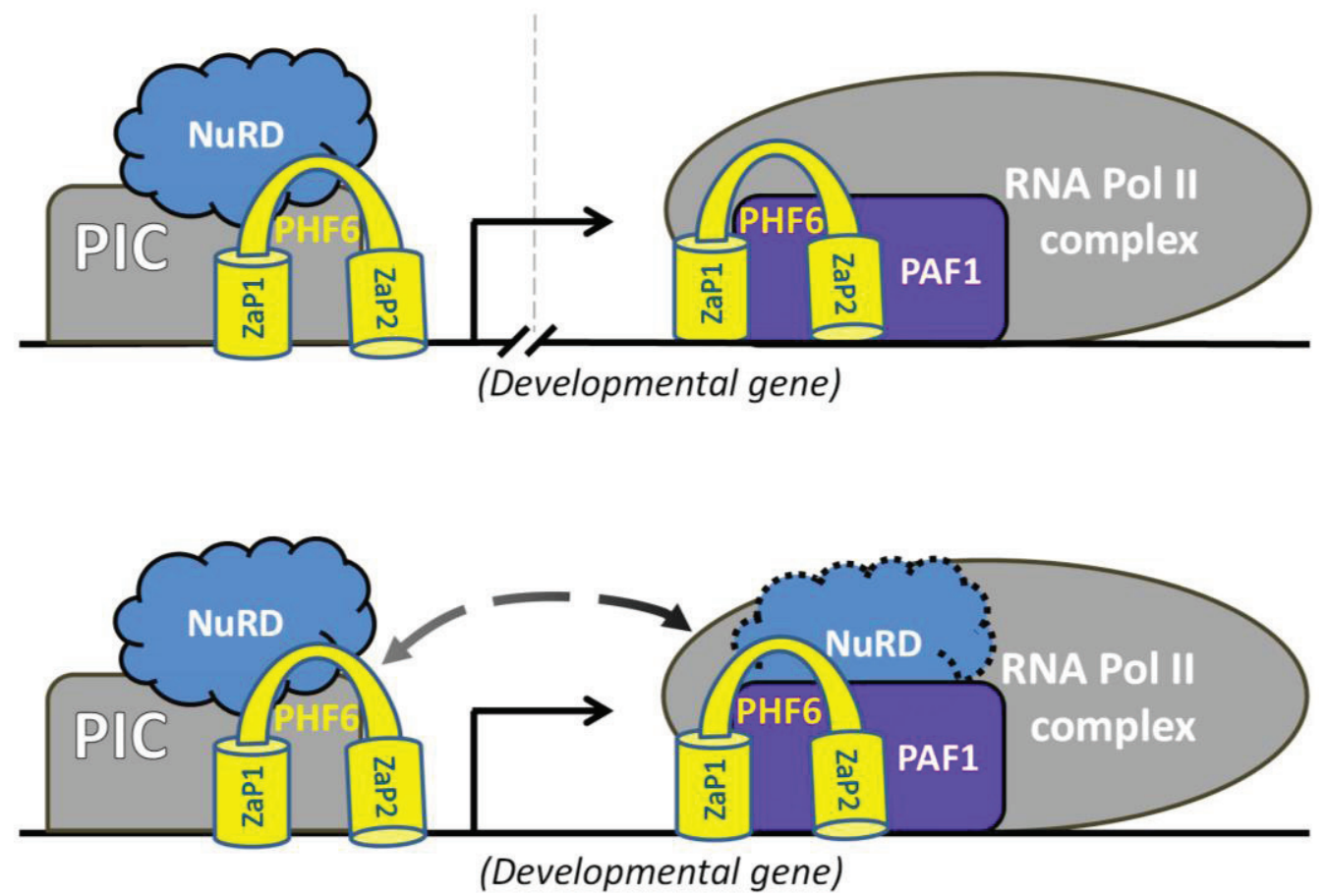

C

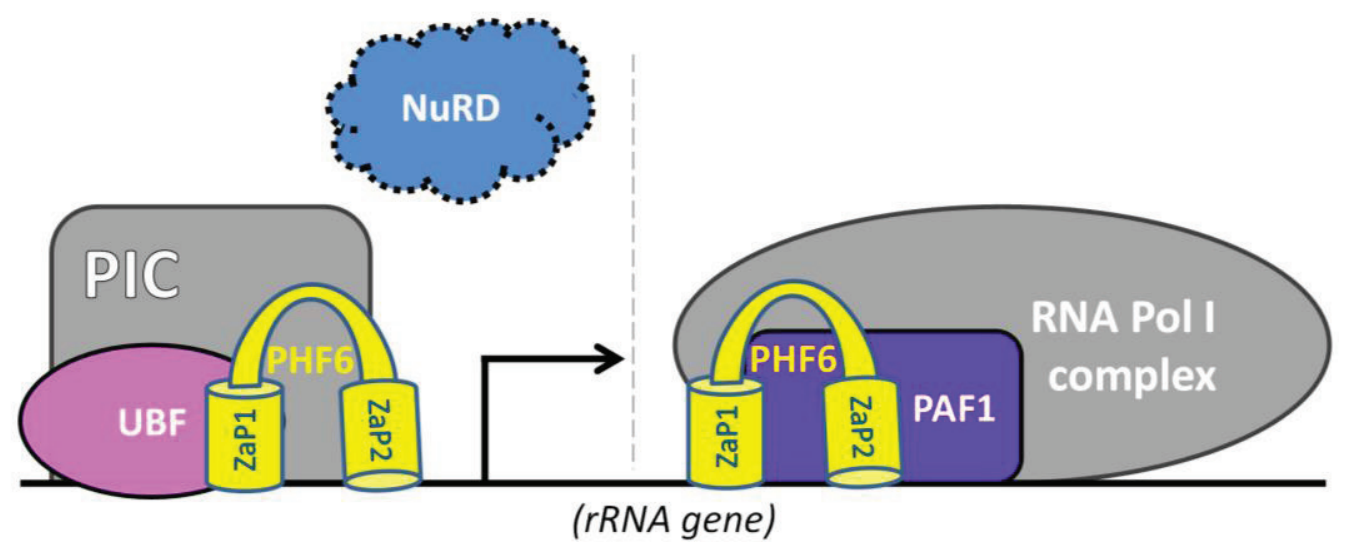

Figure 4. Model for PHF6-dependent transcriptional regulation at developmental or rDNA gene targets. (A) At developmental genes, PHF6 recruits NuRD to promoters to either activate or repress transcription. Similarly, PHF6 can regulate transcriptional elongation at developmental genes through its interaction with the PAF1 complex. (B) Another possible mechanism is that PHF6 interactions with NuRD and PAF1 occur at the same gene whereby PHF6 promotes the formation of a NuRD-PAF1 supercomplex to allow for productive elongation. The existence of a PHF6-mediated supercomplex would be analogous to an IKAROS-driven complex previously described [119]. (C) At rRNA genes, PHF6 interacts with UBF to mediate the initiation of rRNA transcription (left). Promoter regulation may also involve NuRD, although this remains to be shown. Similarly, PHF6-PAF1 may mediate rRNA transcriptional elongation, although experimental validation is still required. 


\subsection{Nucleolar Role of PHF6}

In addition to developmental gene targets, PHF6 may utilize similar complexes to control rDNA transcription, as outlined in Figure 4. In this regard, both NuRD and PAF1 have been demonstrated to contribute to the transcriptional competency of rDNA genes [102,121,122]. Moreover, control of rRNA levels may also involve nucleolar localization of PHF6 since the NuRD interaction motif overlaps with the NoLS and is directly adjacent to the Ser 154/155, which were proposed to be phosphorylated by CDK2 and whose inhibition prevents PHF6 from localizing to the nucleolus [101,113,114]. While it is an attractive hypothesis, further experiments are still required to delineate the importance of PHF6 to the regulation of ribosome biogenesis. Still, the transcription of rRNA accounts for as much as half of all cellular transcription, with ribosome biogenesis rates correlating positively to nucleolar size $[59,123]$.

In many cancers, it is the hyperactivation of ribosome biogenesis that contributes to the pathology, with large nucleoli correlating to poorer clinical outcomes [124]. Given that PHF6 is reported as a negative regulator of rDNA transcription, PHF6 loss-of-function is consistent with increased ribosome biogenesis and contributing to clonal growth in T-ALL. Indeed several T-ALL mutations have been identified in genes encoding ribosomal proteins (e.g.; RPL5, RPL10, RPL11, RPL22), whereas others (e.g., NOTCH1, PTEN, FBXW7) target aspects of the cap-dependent mRNA translation machinery, as has been the subject of recent reviews [125,126]. For some of these genes, a mechanism supporting translational hyperactivation remains unclear, with De Keersmaecker and colleagues arguing for a model where it is the reduction of translational fidelity that contributes to tumorigenesis $[125,126]$. It may also be the case that defective ribosomes, or their individual subunits, have altered extraribosomal functions, allowing tumour cells to overcome cell cycle checkpoints or interfere with tissue-specific developmental pathways [126,127]. In this regard, interactions between PHF6 and ribosomal proteins have been identified and as such, may also impinge upon ribosomal and extraribosomal functions [14].

In neurons, large nucleoli facilitate the sufficient supply of ribosomes to growing neurites to accommodate local demands for translation [128]. Indeed many developmental intellectual disability diseases (e.g., Cockayne syndrome, Rett syndrome) and acquired neurodegenerative disorders (e.g., Alzheimer's disease, Parkinson's disease) are associated with reduced levels of ribosome biogenesis $[129,130]$. Although hyperactive ribosome biogenesis would appear paradoxical with BFLS, a potential explanation may exist by considering the loss of $\mathrm{MeCP} 2$, which is responsible for Rett syndrome [131]. In this example, MeCP2 binds methylated CpG DNA, a mark for rDNA silencing [132], and contributes to heterochromatin formation [133]; yet, rather than hyperactivating rRNA synthesis, the loss of MeCP2 correlates with reduced nucleolar size [134].

\section{Conclusion}

Since the discovery of PHF6 as the cause of BFLS in 2002, the precise function of the protein has remained elusive. Nonetheless, it is becoming clear that PHF6 is a highly dynamic chromatin adaptor protein, containing two $\mathrm{ZaP}$ domains that facilitate its interactions with nucleic acids and a growing number of interaction partners (NuRD, PAF1, UBF) to regulate transcription. Moreover, several potential phosphorylation sites, its interaction with rDNA, and its ability to shuttle between the nucleolus and nucleoplasm suggest that it may be a key regulator of ribosome biogenesis. The generation of 
transgenic mouse models with BFLS-like, T-ALL-like, or AML-like PHF6 mutations, will certainly augment the dissection of the molecular mechanisms driving BFLS and leukemia. In making use of such models, further characterization of the functional roles of PHF6 may thus facilitate the development of novel therapeutics for these distinct disorders.

\section{Acknowledgements}

This work was funded by a Cancer Research Society/University of Ottawa Operating Grant, which is a partnership program between the Cancer Research Society, the Faculty of Medicine of the University of Ottawa and the Ottawa Hospital Research Institute.

\section{Author Contributions}

The manuscript was written by Matthew A.M. Todd and David J. Picketts. Figures and tables were prepared by Matthew A.M. Todd and Danton Ivanochko.

\section{Conflicts of Interest}

The authors declare no conflict of interest.

\section{References and Notes}

1. van Bokhoven, H. Genetic and epigenetic networks in intellectual disabilities. Annu. Rev. Genet. 2011, 45, 81-104.

2. Metzker, M.L. Sequencing technologies - the next generation. Nat. Rev. Genet. 2010, 11, 31-46.

3. Baylin, S.B.; Jones, P.A. A decade of exploring the cancer epigenome-Biological and translational implications. Nat. Rev. Cancer 2011, 11, 726-734.

4. Plass, C.; Pfister, S.M.; Lindroth, A.M.; Bogatyrova, O.; Claus, R.; Lichter, P. Mutations in regulators of the epigenome and their connections to global chromatin patterns in cancer. Nat. Rev. Genet. 2013, 14, 765-780.

5. Schwartzentruber, J.; Korshunov, A.; Liu, X.Y.; Jones, D.T.; Pfaff, E.; Jacob, K.; Sturm, D.; Fontebasso, A.M.; Quang, D.A.; Tonjes, M.; et al. Driver mutations in histone h3.3 and chromatin remodelling genes in paediatric glioblastoma. Nature 2012, 482, 226-231.

6. Dalgliesh, G.L.; Furge, K.; Greenman, C.; Chen, L.; Bignell, G.; Butler, A.; Davies, H.; Edkins, S.; Hardy, C.; Latimer, C.; et al. Systematic sequencing of renal carcinoma reveals inactivation of histone modifying genes. Nature 2010, 463, 360-363.

7. Ehrlich, M.; Buchanan, K.L.; Tsien, F.; Jiang, G.; Sun, B.; Uicker, W.; Weemaes, C.M.; Smeets, D.; Sperling, K.; Belohradsky, B.H.; et al. DNA methyltransferase 3b mutations linked to the icf syndrome cause dysregulation of lymphogenesis genes. Hum. Mol. Genet. 2001, 10, 2917-2931.

8. Cancer Genome Atlas Research. Genomic and epigenomic landscapes of adult de novo acute myeloid leukemia. N. Engl. J. Med. 2013, 368, 2059-2074. 
9. Lower, K.M.; Turner, G.; Kerr, B.A.; Mathews, K.D.; Shaw, M.A.; Gedeon, A.K.; Schelley, S.; Hoyme, H.E.; White, S.M.; Delatycki, M.B.; et al. Mutations in phf6 are associated with borjeson-forssman-lehmann syndrome. Nat. Genet. 2002, 32, 661-665.

10. Van Vlierberghe, P.; Palomero, T.; Khiabanian, H.; Van der Meulen, J.; Castillo, M.; Van Roy, N.; De Moerloose, B.; Philippe, J.; Gonzalez-Garcia, S.; Toribio, M.L.; et al. Phf6 mutations in t-cell acute lymphoblastic leukemia. Nat. Genet. 2010, 42, 338-342.

11. Van Vlierberghe, P.; Patel, J.; Abdel-Wahab, O.; Lobry, C.; Hedvat, C.V.; Balbin, M.; Nicolas, C.; Payer, A.R.; Fernandez, H.F.; Tallman, M.S.; et al. Phf6 mutations in adult acute myeloid leukemia. Leukemia 2011, 25, 130-134.

12. Gerhard, D.S.; Wagner, L.; Feingold, E.A.; Shenmen, C.M.; Grouse, L.H.; Schuler, G.; Klein, S.L.; Old, S.; Rasooly, R.; Good, P.; et al. The status, quality, and expansion of the nih full-length cdna project: The mammalian gene collection $(\mathrm{mgc})$. Genome Res. 2004, 14, 2121-2127.

13. Perry, J. The epc-n domain: A predicted protein-protein interaction domain found in select chromatin associated proteins. BMC Genomics 2006, 7, 6.

14. Todd, M.A.; Picketts, D.J. Phf6 interacts with the nucleosome remodeling and deacetylation (NuRD) complex. J. Proteome Res. 2012, 11, 4326-4337.

15. Landais, S.; Quantin, R.; Rassart, E. Radiation leukemia virus common integration at the kis2 locus: Simultaneous overexpression of a novel noncoding rna and of the proximal phf6 gene. J. Virol 2005, 79, 11443-11456.

16. Vallee, D.; Chevrier, E.; Graham, G.E.; Lazzaro, M.A.; Lavigne, P.A.; Hunter, A.G.; Picketts, D.J. A novel phf6 mutation results in enhanced exon skipping and mild borjesonforssman-lehmann syndrome. J. Med. Genet. 2004, 41, 778-783.

17. Ahmad, Y.; Boisvert, F.M.; Gregor, P.; Cobley, A.; Lamond, A.I. Nopdb: Nucleolar proteome database--2008 update. Nucleic Acids Res. 2009, 37, D181-184.

18. Boisvert, F.M.; Ahmad, Y.; Gierlinski, M.; Charriere, F.; Lamont, D.; Scott, M.; Barton, G.; Lamond, A.I. A quantitative spatial proteomics analysis of proteome turnover in human cells. MCP 2012, 11, M111011429.

19. Voss, A.K.; Gamble, R.; Collin, C.; Shoubridge, C.; Corbett, M.; Gecz, J.; Thomas, T. Protein and gene expression analysis of phf6, the gene mutated in the borjeson-forssman-lehmann syndrome of intellectual disability and obesity. Gene Expr. Patterns 2007, 7, 858-871.

20. Franzoni, E.; Booker, S.A.; Parthasarathy, S.; Rehfeld, F.; Grosser, S.; Srivatsa, S.; Fuchs, H.R.; Tarabykin, V.; Vida, I.; Wulczyn, F.G. Mir-128 regulates neuronal migration, outgrowth and intrinsic excitability via the intellectual disability gene phf6. eLife 2015, 4, doi: 10.7554/eLife.04263.

21. Kent, W.J.; Sugnet, C.W.; Furey, T.S.; Roskin, K.M.; Pringle, T.H.; Zahler, A.M.; Haussler, D. The human genome browser at ucsc. Genome Res. 2002, 12, 996-1006.

22. Palomero, T.; Lim, W.K.; Odom, D.T.; Sulis, M.L.; Real, P.J.; Margolin, A.; Barnes, K.C.; O'Neil, J.; Neuberg, D.; Weng, A.P.; et al. Notch1 directly regulates c-myc and activates a feedforward-loop transcriptional network promoting leukemic cell growth. Proc. Natl. Acad. Sci. USA 2006, 103, 18261-18266. 
23. Kraszewska, M.D.; Dawidowska, M.; Larmonie, N.S.; Kosmalska, M.; Sedek, L.; Szczepaniak, M.; Grzeszczak, W.; Langerak, A.W.; Szczepanski, T.; Witt, M. DNA methylation pattern is altered in childhood t-cell acute lymphoblastic leukemia patients as compared with normal thymic subsets: Insights into cpg island methylator phenotype in t-all. Leukemia 2012, 26, 367-371.

24. Mavrakis, K.J.; Van Der Meulen, J.; Wolfe, A.L.; Liu, X.; Mets, E.; Taghon, T.; Khan, A.A.; Setty, M.; Rondou, P.; Vandenberghe, P.; et al. A cooperative microrna-tumor suppressor gene network in acute t-cell lymphoblastic leukemia (t-all). Nat. Genet. 2011, 43, 673-678.

25. Mets, E.; Van Peer, G.; Van der Meulen, J.; Boice, M.; Taghon, T.; Goossens, S.; Mestdagh, P.; Benoit, Y.; De Moerloose, B.; Van Roy, N.; et al. Microrna-128-3p is a novel oncomir targeting phf6 in t-cell acute lymphoblastic leukemia. Haematologica 2014.

26. Borjeson, M.; Forssman, H.; Lehmann, O. An x-linked, recessively inherited syndrome characterized by grave mental deficiency, epilepsy, and endocrine disorder. Acta medica Scandinavica 1962, $171,13-21$.

27. Turner, G.; Lower, K.M.; White, S.M.; Delatycki, M.; Lampe, A.K.; Wright, M.; Smith, J.C.; Kerr, B.; Schelley, S.; Hoyme, H.E.; et al. The clinical picture of the borjeson-forssman-lehmann syndrome in males and heterozygous females with phf6 mutations. Clin. Genet. 2004, 65, $226-232$.

28. Gecz, J.; Turner, G.; Nelson, J.; Partington, M. The borjeson-forssman-lehman syndrome (bfls, mim \#301900). Eur. J. Hum. Genet. 2006, 14, 1233-1237.

29. Carter, M.T.; Picketts, D.J.; Hunter, A.G.; Graham, G.E. Further clinical delineation of the borjeson-forssman-lehmann syndrome in patients with phf6 mutations. Am. J. Med. Genet. A 2009, 149A, 246-250.

30. Zweier, C.; Rittinger, O.; Bader, I.; Berland, S.; Cole, T.; Degenhardt, F.; Di Donato, N.; Graul-Neumann, L.; Hoyer, J.; Lynch, S.A.; et al. Females with de novo aberrations in phf6: Clinical overlap of borjeson-forssman-lehmann with coffin-siris syndrome. Am. J. Med. Genet. Part C Semin. Med. Genet. 2014, 166C, 290-301.

31. Chao, M.M.; Todd, M.A.; Kontny, U.; Neas, K.; Sullivan, M.J.; Hunter, A.G.; Picketts, D.J.; Kratz, C.P. T-cell acute lymphoblastic leukemia in association with borjeson-forssman-lehmann syndrome due to a mutation in phf6. Pediatr. Blood Cancer 2010, 55, 722-724.

32. Crawford, J.; Lower, K.M.; Hennekam, R.C.; Van Esch, H.; Megarbane, A.; Lynch, S.A.; Turner, G.; Gecz, J. Mutation screening in borjeson-forssman-lehmann syndrome: Identification of a novel de novo phf6 mutation in a female patient. J. Med. Genet. 2006, 43, 238-243.

33. Gedeon, A.K.; Kozman, H.M.; Robinson, H.; Pilia, G.; Schlessinger, D.; Turner, G.; Mulley, J.C. Refinement of the background genetic map of xq26-q27 and gene localisation for borjesonforssman-lehmann syndrome. Am. J. Med. Genet. 1996, 64, 63-68.

34. Mathews, K.D.; Ardinger, H.H.; Nishimura, D.Y.; Buetow, K.H.; Murray, J.C.; Bartley, J.A. Linkage localization of borjeson-forssman-lehmann syndrome. Am. J. Med. Genet. 1989, 34, 470-474.

35. Turner, G.; Gedeon, A.; Mulley, J.; Sutherland, G.; Rae, J.; Power, K.; Arthur, I. Borjeson-forssman-lehmann syndrome: Clinical manifestations and gene localization to xq2627. Am. J. Med. Genet. 1989, 34, 463-469. 
36. Stevenson, R.E.; Schwartz, C.; Schroer, R.J. X-Linked Mental Retardation (Oxford Monographs on Medical Genetics, No. 39); Oxford University Press: New York, USA, 2000; pp. 134-138.

37. Kosho, T.; Miyake, N.; Carey, J.C. Coffin-siris syndrome and related disorders involving components of the baf (mswi/snf) complex: Historical review and recent advances using next generation sequencing. Am. J. Med. Genet. Part C Semin. Med. Genet. 2014, 166C, 241-251.

38. Kosho, T.; Okamoto, N.; Coffin-Siris Syndrome International. Genotype-phenotype correlation of coffin-siris syndrome caused by mutations in smarcb1, smarca4, smarce1, and arid1a. Am. J. Med. Genet. Part C Semin. Med. Genet. 2014, 166C, 262-275.

39. Coffin, G.S.; Siris, E. Mental retardation with absent fifth fingernail and terminal phalanx. Am. J. Dis. Children 1970, 119, 433-439.

40. Tsurusaki, Y.; Okamoto, N.; Ohashi, H.; Kosho, T.; Imai, Y.; Hibi-Ko, Y.; Kaname, T.; Naritomi, K.; Kawame, H.; Wakui, K.; et al. Mutations affecting components of the swi/snf complex cause coffin-siris syndrome. Nat. Genet. 2012, 44, 376-378.

41. Wieczorek, D.; Bogershausen, N.; Beleggia, F.; Steiner-Haldenstatt, S.; Pohl, E.; Li, Y.; Milz, E.; Martin, M.; Thiele, H.; Altmuller, J.; et al. A comprehensive molecular study on coffin-siris and nicolaides-baraitser syndromes identifies a broad molecular and clinical spectrum converging on altered chromatin remodeling. Hum. Mol. Genet. 2013, 22, 5121-5135.

42. Zweier, C.; Kraus, C.; Brueton, L.; Cole, T.; Degenhardt, F.; Engels, H.; Gillessen-Kaesbach, G.; Graul-Neumann, L.; Horn, D.; Hoyer, J.; et al. A new face of borjeson-forssman-lehmann syndrome? De novo mutations in phf6 in seven females with a distinct phenotype. J. Med. Genet. 2013, 50, 838-847.

43. Berland, S.; Alme, K.; Brendehaug, A.; Houge, G.; Hovland, R. Phf6 deletions may cause borjeson-forssman-lehmann syndrome in females. Mol. Syndromol 2011, 1, 294-300.

44. Di Donato, N.; Isidor, B.; Lopez Cazaux, S.; Le Caignec, C.; Klink, B.; Kraus, C.; Schrock, E.; Hackmann, K. Distinct phenotype of phf6 deletions in females. Eur J. Med. Genet. 2014, 57, 85-89.

45. Mangelsdorf, M.; Chevrier, E.; Mustonen, A.; Picketts, D.J. Borjeson-forssman-lehmann syndrome due to a novel plant homeodomain zinc finger mutation in the phf6 gene. J. Child. Neurol 2009, 24, 610-614.

46. Baumstark, A.; Lower, K.M.; Sinkus, A.; Andriuskeviciute, I.; Jurkeniene, L.; Gecz, J.; Just, W. Novel phf6 mutation p.D333del causes borjeson-forssman-lehmann syndrome. J. Med. Genet. 2003, 40, e50.

47. Grossmann, V.; Haferlach, C.; Weissmann, S.; Roller, A.; Schindela, S.; Poetzinger, F.; Stadler, K.; Bellos, F.; Kern, W.; Haferlach, T.; et al. The molecular profile of adult t-cell acute lymphoblastic leukemia: Mutations in runx1 and dnmt3a are associated with poor prognosis in tall. Genes Chromosomes Cancer 2013, 52, 410-422.

48. Wang, Q.; Qiu, H.; Jiang, H.; Wu, L.; Dong, S.; Pan, J.; Wang, W.; Ping, N.; Xia, J.; Sun, A.; et al. Mutations of phf6 are associated with mutations of notch1, jak1 and rearrangement of setnup214 in t-cell acute lymphoblastic leukemia. Haematologica 2011, 96, 1808-1814.

49. Yoo, N.J.; Kim, Y.R.; Lee, S.H. Somatic mutation of phf6 gene in t-cell acute lymphoblatic leukemia, acute myelogenous leukemia and hepatocellular carcinoma. Acta Oncol. 2012, 51, $107-111$. 
50. Huh, H.J.; Lee, S.H.; Yoo, K.H.; Sung, K.W.; Koo, H.H.; Jang, J.H.; Kim, K.; Kim, S.J.; Kim, W.S.; Jung, C.W.; et al. Gene mutation profiles and prognostic implications in korean patients with t-lymphoblastic leukemia. Ann. Hematol 2013, 92, 635-644.

51. Naito, T.; Tanaka, H.; Naoe, Y.; Taniuchi, I. Transcriptional control of t-cell development. Int. Immunol. 2011, 23, 661-668.

52. Van Vlierberghe, P.; Ferrando, A. The molecular basis of t cell acute lymphoblastic leukemia. J. Clin. Invest. 2012, 122, 3398-3406.

53. Ferrando, A.A.; Neuberg, D.S.; Staunton, J.; Loh, M.L.; Huard, C.; Raimondi, S.C.; Behm, F.G.; Pui, C.H.; Downing, J.R.; Gilliland, D.G.; et al. Gene expression signatures define novel oncogenic pathways in t cell acute lymphoblastic leukemia. Cancer Cell 2002, 1, 75-87.

54. De Keersmaecker, K.; Real, P.J.; Gatta, G.D.; Palomero, T.; Sulis, M.L.; Tosello, V.; Van Vlierberghe, P.; Barnes, K.; Castillo, M.; Sole, X.; et al. The tlx1 oncogene drives aneuploidy in t cell transformation. Nat. Med. 2010, 16, 1321-1327.

55. Weng, A.P.; Ferrando, A.A.; Lee, W.; Morris, J.P.t.; Silverman, L.B.; Sanchez-Irizarry, C.; Blacklow, S.C.; Look, A.T.; Aster, J.C. Activating mutations of notch1 in human t cell acute lymphoblastic leukemia. Science 2004, 306, 269-271.

56. Patel, J.P.; Gonen, M.; Figueroa, M.E.; Fernandez, H.; Sun, Z.; Racevskis, J.; Van Vlierberghe, P.; Dolgalev, I.; Thomas, S.; Aminova, O.; et al. Prognostic relevance of integrated genetic profiling in acute myeloid leukemia. N. Engl. J. Med. 2012, 366, 1079-1089.

57. Li, X.; Yao, H.; Chen, Z.; Wang, Q.; Zhao, Y.; Chen, S. Somatic mutations of phf6 in patients with chronic myeloid leukemia in blast crisis. Leuk Lymphoma 2013, 54, 671-672.

58. Meacham, C.E.; Lawton, L.N.; Soto-Feliciano, Y.M.; Pritchard, J.R.; Joughin, B.A.; Ehrenberger, T.; Fenouille, N.; Zuber, J.; Williams, R.T.; Young, R.A.; et al. A genome-scale in vivo loss-of-function screen identifies phf6 as a lineage-specific regulator of leukemia cell growth. Genes Dev. 2015, 29, 483-488.

59. Wang, J.; Leung, J.W.; Gong, Z.; Feng, L.; Shi, X.; Chen, J. Phf6 regulates cell cycle progression by suppressing ribosomal rna synthesis. J. Biol. Chem. 2013, 288, 3174-3183.

60. Wakabayashi, Y.; Watanabe, H.; Inoue, J.; Takeda, N.; Sakata, J.; Mishima, Y.; Hitomi, J.; Yamamoto, T.; Utsuyama, M.; Niwa, O.; et al. Bcl11b is required for differentiation and survival of alphabeta t lymphocytes. Nat. Immunol. 2003, 4, 533-539.

61. Aasland, R.; Gibson, T.J.; Stewart, A.F. The phd finger: Implications for chromatin-mediated transcriptional regulation. Trends Biochem. Sci 1995, 20, 56-59.

62. Capili, A.D.; Schultz, D.C.; Rauscher, I.F.; Borden, K.L. Solution structure of the phd domain from the kap-1 corepressor: Structural determinants for phd, ring and lim zinc-binding domains. Embo J. 2001, 20, 165-177.

63. Li, H.; Ilin, S.; Wang, W.; Duncan, E.M.; Wysocka, J.; Allis, C.D.; Patel, D.J. Molecular basis for site-specific read-out of histone h3k4me3 by the bptf phd finger of nurf. Nature 2006, 442, 91-95.

64. Shi, X.; Hong, T.; Walter, K.L.; Ewalt, M.; Michishita, E.; Hung, T.; Carney, D.; Pena, P.; Lan, F.; Kaadige, M.R.; et al. Ing2 phd domain links histone h3 lysine 4 methylation to active gene repression. Nature 2006, 442, 96-99. 
65. Mansfield, R.E.; Musselman, C.A.; Kwan, A.H.; Oliver, S.S.; Garske, A.L.; Davrazou, F.; Denu, J.M.; Kutateladze, T.G.; Mackay, J.P. Plant homeodomain (phd) fingers of chd4 are histone h3binding modules with preference for unmodified h3k4 and methylated h3k9. J. Biol. Chem. 2011, 286, 11779-11791.

66. Lange, M.; Kaynak, B.; Forster, U.B.; Tonjes, M.; Fischer, J.J.; Grimm, C.; Schlesinger, J.; Just, S.; Dunkel, I.; Krueger, T.; et al. Regulation of muscle development by dpf3, a novel histone acetylation and methylation reader of the baf chromatin remodeling complex. Genes Dev. 2008, 22, 2370-2384.

67. Zeng, L.; Zhang, Q.; Li, S.; Plotnikov, A.N.; Walsh, M.J.; Zhou, M.M. Mechanism and regulation of acetylated histone binding by the tandem phd finger of dpf3b. Nature 2010, 466, $258-262$.

68. Liu, L.; Qin, S.; Zhang, J.; Ji, P.; Shi, Y.; Wu, J. Solution structure of an atypical phd finger in brpf2 and its interaction with DNA. J. Struct. Biol. 2012, 180, 165-173.

69. Liu, Z.; Li, F.; Ruan, K.; Zhang, J.; Mei, Y.; Wu, J.; Shi, Y. Structural and functional insights into the human borjeson-forssman-lehmann syndrome-associated protein phf6. J. Biol. Chem. 2014, 289, 10069-10083.

70. Castello, A.; Fischer, B.; Eichelbaum, K.; Horos, R.; Beckmann, B.M.; Strein, C.; Davey, N.E.; Humphreys, D.T.; Preiss, T.; Steinmetz, L.M.; et al. Insights into rna biology from an atlas of mammalian mrna-binding proteins. Cell 2012, 149, 1393-1406.

71. Hendrich, B.; Guy, J.; Ramsahoye, B.; Wilson, V.A.; Bird, A. Closely related proteins mbd2 and mbd3 play distinctive but interacting roles in mouse development. Genes Dev. 2001, 15, $710-723$.

72. Lai, A.Y.; Wade, P.A. Cancer biology and nurd: A multifaceted chromatin remodelling complex. Nat. Rev. Cancer 2011, 11, 588-596.

73. Potts, R.C.; Zhang, P.; Wurster, A.L.; Precht, P.; Mughal, M.R.; Wood, W.H., 3rd; Zhang, Y.; Becker, K.G.; Mattson, M.P.; Pazin, M.J. Chd5, a brain-specific paralog of mi2 chromatin remodeling enzymes, regulates expression of neuronal genes. PLoS One 2011, 6, e24515.

74. Yoshida, T.; Hazan, I.; Zhang, J.; Ng, S.Y.; Naito, T.; Snippert, H.J.; Heller, E.J.; Qi, X.; Lawton, L.N.; Williams, C.J.; et al. The role of the chromatin remodeler mi-2beta in hematopoietic stem cell self-renewal and multilineage differentiation. Genes Dev. 2008, 22, 1174-1189.

75. Reynolds, N.; Latos, P.; Hynes-Allen, A.; Loos, R.; Leaford, D.; O'Shaughnessy, A.; Mosaku, O.; Signolet, J.; Brennecke, P.; Kalkan, T.; et al. Nurd suppresses pluripotency gene expression to promote transcriptional heterogeneity and lineage commitment. Cell. Stem Cell 2012, 10, 583-594.

76. Yamada, T.; Yang, Y.; Hemberg, M.; Yoshida, T.; Cho, H.Y.; Murphy, J.P.; Fioravante, D.; Regehr, W.G.; Gygi, S.P.; Georgopoulos, K.; et al. Promoter decommissioning by the nurd chromatin remodeling complex triggers synaptic connectivity in the mammalian brain. Neuron 2014, 83, 122-134.

77. Reynolds, N.; Salmon-Divon, M.; Dvinge, H.; Hynes-Allen, A.; Balasooriya, G.; Leaford, D.; Behrens, A.; Bertone, P.; Hendrich, B. Nurd-mediated deacetylation of h3k27 facilitates 
recruitment of polycomb repressive complex 2 to direct gene repression. EMBO J. 2012, 31, $593-605$.

78. Zhang, J.; Jackson, A.F.; Naito, T.; Dose, M.; Seavitt, J.; Liu, F.; Heller, E.J.; Kashiwagi, M.; Yoshida, T.; Gounari, F.; et al. Harnessing of the nucleosome-remodeling-deacetylase complex controls lymphocyte development and prevents leukemogenesis. Nat. Immunol. 2012, 13, 86-94.

79. Tong, J.K.; Hassig, C.A.; Schnitzler, G.R.; Kingston, R.E.; Schreiber, S.L. Chromatin deacetylation by an atp-dependent nucleosome remodelling complex. Nature 1998, 395, 917-921.

80. Zhang, Y.; LeRoy, G.; Seelig, H.P.; Lane, W.S.; Reinberg, D. The dermatomyositis-specific autoantigen mi2 is a component of a complex containing histone deacetylase and nucleosome remodeling activities. Cell 1998, 95, 279-289.

81. Williams, C.J.; Naito, T.; Arco, P.G.; Seavitt, J.R.; Cashman, S.M.; De Souza, B.; Qi, X.; Keables, P.; Von Andrian, U.H.; Georgopoulos, K. The chromatin remodeler mi-2beta is required for cd4 expression and t cell development. Immunity 2004, 20, 719-733.

82. Wang, Y.; Zhang, H.; Chen, Y.; Sun, Y.; Yang, F.; Yu, W.; Liang, J.; Sun, L.; Yang, X.; Shi, L.; et al. Lsd1 is a subunit of the nurd complex and targets the metastasis programs in breast cancer. Cell 2009, 138, 660-672.

83. Molnar, A.; Georgopoulos, K. The ikaros gene encodes a family of functionally diverse zinc finger DNA-binding proteins. Mol. Cell. Biol. 1994, 14, 8292-8303.

84. Yamashita, K.; Sato, A.; Asashima, M.; Wang, P.C.; Nishinakamura, R. Mouse homolog of sall1, a causative gene for townes-brocks syndrome, binds to a/t-rich sequences in pericentric heterochromatin via its c-terminal zinc finger domains. Genet. Cells 2007, 12, 171-182.

85. Lauberth, S.M.; Bilyeu, A.C.; Firulli, B.A.; Kroll, K.L.; Rauchman, M. A phosphomimetic mutation in the sall1 repression motif disrupts recruitment of the nucleosome remodeling and deacetylase complex and repression of gbx2. J. Biol. Chem. 2007, 282, 34858-34868.

86. Tang, B.; Di Lena, P.; Schaffer, L.; Head, S.R.; Baldi, P.; Thomas, E.A. Genome-wide identification of bcl11b gene targets reveals role in brain-derived neurotrophic factor signaling. PLoS One 2011, 6, e23691.

87. Zhang, C.; Mejia, L.A.; Huang, J.; Valnegri, P.; Bennett, E.J.; Anckar, J.; Jahani-Asl, A.; Gallardo, G.; Ikeuchi, Y.; Yamada, T.; et al. The x-linked intellectual disability protein phf6 associates with the pafl complex and regulates neuronal migration in the mammalian brain. Neuron 2013, 78, 986-993.

88. Doyon, Y.; Cayrou, C.; Ullah, M.; Landry, A.J.; Cote, V.; Selleck, W.; Lane, W.S.; Tan, S.; Yang, X.J.; Cote, J. Ing tumor suppressor proteins are critical regulators of chromatin acetylation required for genome expression and perpetuation. Mol. Cell. 2006, 21, 51-64.

89. Brooks, W.S.; Helton, E.S.; Banerjee, S.; Venable, M.; Johnson, L.; Schoeb, T.R.; Kesterson, R.A.; Crawford, D.F. G2e3 is a dual function ubiquitin ligase required for early embryonic development. J. Biol. Chem. 2008, 283, 22304-22315.

90. Whetstine, J.R.; Nottke, A.; Lan, F.; Huarte, M.; Smolikov, S.; Chen, Z.; Spooner, E.; Li, E.; Zhang, G.; Colaiacovo, M.; et al. Reversal of histone lysine trimethylation by the jmjd2 family of histone demethylases. Cell 2006, 125, 467-481. 
91. Nakamura, T.; Mori, T.; Tada, S.; Krajewski, W.; Rozovskaia, T.; Wassell, R.; Dubois, G.; Mazo, A.; Croce, C.M.; Canaani, E. All-1 is a histone methyltransferase that assembles a supercomplex of proteins involved in transcriptional regulation. Mol. Cell. 2002, 10, 1119-1128.

92. Mo, R.; Rao, S.M.; Zhu, Y.J. Identification of the mll2 complex as a coactivator for estrogen receptor alpha. J. Biol. Chem. 2006, 281, 15714-15720.

93. Cho, Y.W.; Hong, T.; Hong, S.; Guo, H.; Yu, H.; Kim, D.; Guszczynski, T.; Dressler, G.R.; Copeland, T.D.; Kalkum, M.; et al. Ptip associates with mll3- and mll4-containing histone h3 lysine 4 methyltransferase complex. J. Biol. Chem. 2007, 282, 20395-20406.

94. Yang, S.Y.; Baxter, E.M.; Van Doren, M. Phf7 controls male sex determination in the drosophila germline. Dev. Cell 2012, 22, 1041-1051.

95. Clarke, E.; Rahman, N.; Page, N.; Rolph, M.S.; Stewart, G.J.; Jones, G.J. Functional characterization of the atopy-associated gene phf11. J. Allergy Clin. Immunol. 2008, 121, 1148-1154.

96. Kitagawa, M.; Takebe, A.; Ono, Y.; Imai, T.; Nakao, K.; Nishikawa, S.; Era, T. Phf14, a novel regulator of mesenchyme growth via platelet-derived growth factor (pdgf) receptor-alpha. J. Biol. Chem. 2012, 287, 27983-27996.

97. Bi, W.; Saifi, G.M.; Shaw, C.J.; Walz, K.; Fonseca, P.; Wilson, M.; Potocki, L.; Lupski, J.R. Mutations of rail, a phd-containing protein, in nondeletion patients with smith-magenis syndrome. Human Genet. 2004, 115, 515-524.

98. Rekdal, C.; Sjottem, E.; Johansen, T. The nuclear factor spbp contains different functional domains and stimulates the activity of various transcriptional activators. J. Biol. Chem. 2000, 275, 40288-40300.

99. Lauberth, S.M.; Rauchman, M. A conserved 12-amino acid motif in sall1 recruits the nucleosome remodeling and deacetylase corepressor complex. J. Biol. Chem. 2006, 281, 2392223931.

100. Lejon, S.; Thong, S.Y.; Murthy, A.; AlQarni, S.; Murzina, N.V.; Blobel, G.A.; Laue, E.D.; Mackay, J.P. Insights into association of the nurd complex with fog-1 from the crystal structure of an rbap48.Fog-1 complex. J. Biol. Chem. 2011, 286, 1196-1203.

101. Liu, Z.; Li, F.; Zhang, B.; Li, S.; Wu, J.; Shi, Y. Structural basis of plant homeodomain finger 6 (phf6) recognition by the retinoblastoma binding protein 4 (rbbp4) component of the nucleosome remodeling and deacetylase (nurd) complex. J. Biol. Chem. 2015, 290, 6630-6638.

102. Zhang, Y.; Smith, A.D.t.; Renfrow, M.B.; Schneider, D.A. The rna polymerase-associated factor 1 complex (paflc) directly increases the elongation rate of rna polymerase $\mathrm{i}$ and is required for efficient regulation of rrna synthesis. J. Biol. Chem. 2010, 285, 14152-14159.

103. Learned, R.M.; Learned, T.K.; Haltiner, M.M.; Tjian, R.T. Human rrna transcription is modulated by the coordinate binding of two factors to an upstream control element. Cell 1986, 45, 847-857.

104. Bell, S.P.; Learned, R.M.; Jantzen, H.M.; Tjian, R. Functional cooperativity between transcription factors ubf1 and sl1 mediates human ribosomal rna synthesis. Science 1988, 241, 1192-1197. 
105. Matsuoka, S.; Ballif, B.A.; Smogorzewska, A.; McDonald, E.R., 3rd; Hurov, K.E.; Luo, J.; Bakalarski, C.E.; Zhao, Z.; Solimini, N.; Lerenthal, Y.; et al. Atm and atr substrate analysis reveals extensive protein networks responsive to DNA damage. Science 2007, 316, 1160-1166.

106. Dephoure, N.; Zhou, C.; Villen, J.; Beausoleil, S.A.; Bakalarski, C.E.; Elledge, S.J.; Gygi, S.P. A quantitative atlas of mitotic phosphorylation. Proc. Natl Acad Sci U S A 2008, 105, 10762-10767.

107. Mayya, V.; Lundgren, D.H.; Hwang, S.I.; Rezaul, K.; Wu, L.; Eng, J.K.; Rodionov, V.; Han, D.K. Quantitative phosphoproteomic analysis of $\mathrm{t}$ cell receptor signaling reveals system-wide modulation of protein-protein interactions. Sci. Signal. 2009, 2, ra46.

108. Kettenbach, A.N.; Schweppe, D.K.; Faherty, B.K.; Pechenick, D.; Pletnev, A.A.; Gerber, S.A. Quantitative phosphoproteomics identifies substrates and functional modules of aurora and pololike kinase activities in mitotic cells. Sci. Signal. 2011, 4, rs5.

109. Kruhlak, M.; Crouch, E.E.; Orlov, M.; Montano, C.; Gorski, S.A.; Nussenzweig, A.; Misteli, T.; Phair, R.D.; Casellas, R. The atm repair pathway inhibits rna polymerase i transcription in response to chromosome breaks. Nature 2007, 447, 730-734.

110. Nakajima, H.; Toyoshima-Morimoto, F.; Taniguchi, E.; Nishida, E. Identification of a consensus motif for plk (polo-like kinase) phosphorylation reveals myt1 as a plk1 substrate. J. Biol. Chem. 2003, 278, 25277-25280.

111. Elia, A.E.; Cantley, L.C.; Yaffe, M.B. Proteomic screen finds pser/pthr-binding domain localizing plk1 to mitotic substrates. Science 2003, 299, 1228-1231.

112. Grosstessner-Hain, K.; Hegemann, B.; Novatchkova, M.; Rameseder, J.; Joughin, B.A.; Hudecz, O.; Roitinger, E.; Pichler, P.; Kraut, N.; Yaffe, M.B.; et al. Quantitative phospho-proteomics to investigate the polo-like kinase 1-dependent phospho-proteome. MCP 2011, 10, M111 008540.

113. Chi, Y.; Welcker, M.; Hizli, A.A.; Posakony, J.J.; Aebersold, R.; Clurman, B.E. Identification of cdk2 substrates in human cell lysates. Genome Biol. 2008, 9, R149.

114. Kustatscher, G.; Hegarat, N.; Wills, K.L.; Furlan, C.; Bukowski-Wills, J.C.; Hochegger, H.; Rappsilber, J. Proteomics of a fuzzy organelle: Interphase chromatin. EMBO J. 2014, 33, 648-664.

115. Lapenna, S.; Giordano, A. Cell cycle kinases as therapeutic targets for cancer. Nature Rev. Drug Discovery 2009, 8, 547-566.

116. Montanaro, L.; Trere, D.; Derenzini, M. Nucleolus, ribosomes, and cancer. Am. J. Pathol. 2008, 173, 301-310.

117. Kim, J.; Sif, S.; Jones, B.; Jackson, A.; Koipally, J.; Heller, E.; Winandy, S.; Viel, A.; Sawyer, A.; Ikeda, T.; et al. Ikaros DNA-binding proteins direct formation of chromatin remodeling complexes in lymphocytes. Immunity 1999, 10, 345-355.

118. Bottardi, S.; Mavoungou, L.; Bourgoin, V.; Mashtalir, N.; Affar el, B.; Milot, E. Direct protein interactions are responsible for ikaros-gata and ikaros-cdk9 cooperativeness in hematopoietic cells. Mol. Cell. Biol. 2013, 33, 3064-3076.

119. Bottardi, S.; Mavoungou, L.; Pak, H.; Daou, S.; Bourgoin, V.; Lakehal, Y.A.; Affar el, B.; Milot, E. The ikaros interaction with a complex including chromatin remodeling and transcription elongation activities is required for hematopoiesis. PLoS Genet. 2014, 10, e1004827. 
120. Shimbo, T.; Du, Y.; Grimm, S.A.; Dhasarathy, A.; Mav, D.; Shah, R.R.; Shi, H.; Wade, P.A. Mbd3 localizes at promoters, gene bodies and enhancers of active genes. PLoS Genet. 2013, 9, e1004028.

121. Xie, W.; Ling, T.; Zhou, Y.; Feng, W.; Zhu, Q.; Stunnenberg, H.G.; Grummt, I.; Tao, W. The chromatin remodeling complex nurd establishes the poised state of rrna genes characterized by bivalent histone modifications and altered nucleosome positions. Proc. Natl. Acad. Sci. USA 2012, 109, 8161-8166.

122. Ling, T.; Xie, W.; Luo, M.; Shen, M.; Zhu, Q.; Zong, L.; Zhou, T.; Gu, J.; Lu, Z.; Zhang, F.; et al. Chd4/nurd maintains demethylation state of rdna promoters through inhibiting the expression of the rdna methyltransferase recruiter tip5. Biochem. Biophys. Res. Commun. 2013, 437, 101-107.

123. Hamperl, S.; Wittner, M.; Babl, V.; Perez-Fernandez, J.; Tschochner, H.; Griesenbeck, J. Chromatin states at ribosomal DNA loci. Biochimica et biophysica acta 2013, 1829, 405-417.

124. Derenzini, M.; Montanaro, L.; Trere, D. What the nucleolus says to a tumour pathologist. Histopathology 2009, 54, 753-762.

125. Girardi, T.; De Keersmaecker, K. T-all: All a matter of translation? Haematologica 2015, 100, 293-295.

126. De Keersmaecker, K.; Sulima, S.O.; Dinman, J.D. Ribosomopathies and the paradox of cellular hypo- to hyperproliferation. Blood 2015, 125, 1377-1382.

127. Warner, J.R.; McIntosh, K.B. How common are extraribosomal functions of ribosomal proteins? Mol. Cell. 2009, 34, 3-11.

128. Gomes, C.; Smith, S.C.; Youssef, M.N.; Zheng, J.J.; Hagg, T.; Hetman, M. Rna polymerase 1-driven transcription as a mediator of bdnf-induced neurite outgrowth. J. Biol. Chem. 2011, 286, 4357-4363.

129. Hannan, K.M.; Sanij, E.; Rothblum, L.I.; Hannan, R.D.; Pearson, R.B. Dysregulation of rna polymerase i transcription during disease. Biochimica et biophysica acta 2013, 1829, 342-360.

130. Hetman, M.; Pietrzak, M. Emerging roles of the neuronal nucleolus. Trends Neurosci. 2012, 35, 305-314.

131. Amir, R.E.; Van den Veyver, I.B.; Wan, M.; Tran, C.Q.; Francke, U.; Zoghbi, H.Y. Rett syndrome is caused by mutations in $\mathrm{x}$-linked mecp2, encoding methyl-cpg-binding protein 2 . Nat. Genet. 1999, 23, 185-188.

132. Santoro, R.; Grummt, I. Molecular mechanisms mediating methylation-dependent silencing of ribosomal gene transcription. Mol. Cell. 2001, 8, 719-725.

133. Brero, A.; Easwaran, H.P.; Nowak, D.; Grunewald, I.; Cremer, T.; Leonhardt, H.; Cardoso, M.C. Methyl cpg-binding proteins induce large-scale chromatin reorganization during terminal differentiation. J. Cell Biol. 2005, 169, 733-743.

134. Singleton, M.K.; Gonzales, M.L.; Leung, K.N.; Yasui, D.H.; Schroeder, D.I.; Dunaway, K.; LaSalle, J.M. Mecp2 is required for global heterochromatic and nucleolar changes during activity-dependent neuronal maturation. Neurobiol. Dis. 2011, 43, 190-200.

(C) 2015 by the authors; licensee MDPI, Basel, Switzerland. This article is an open access article distributed under the terms and conditions of the Creative Commons Attribution license (http://creativecommons.org/licenses/by/4.0/). 